\title{
ANALYSIS OF LABORATORY TEST DATA TO DERIVE SOIL CONSTITUTIVE PROPERTIES
}

\author{
by
}

J. G. Jackson, Jr.

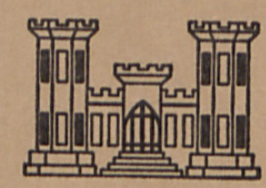

April 1969

Sponsored by

Defense Atomic Support Agency

\section{Conducted by}

U. S. Army Engineer Waterways Experiment Station CORPS OF ENGINEERS

\section{Vicksburg, Mississippi}

THIS DOCUMENT HAS BEEN APPROVED FOR PUBLIC RELEASE AND SALE; ITS DISTRIBUTION IS UNLIMITED 


\section{ANALYSIS OF LABORATORY TEST DATA TO DERIVE SOIL CONSTITUTIVE PROPERTIES}

by

J. G. Jackson, Jr.

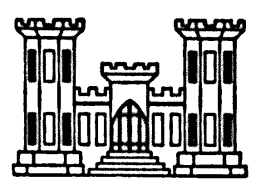

April 1969

Sponsored by

Defense Atomic Support Agency

Conducted by

U. S. Army Engineer Waterways Experiment Station CORPS OF ENGINEERS

Vicksburg, Mississippi

ARMY.MRC VICKBBURG. MISS.

THIS DOCUMENT HAS BEEN APPROVED FOR PUBLIC RELEASE AND SALE; ITS DISTRIBUTION IS UNLIMITED 


\section{Foreword}

This paper was prepared for presentation at the Defense Atomic Support Agency (DASA) Strategic Structures Vulnerability/Hardening Long Range Planning Meeting held at the U. S. Army Engineer Waterways Experiment Station (WES), Vicksburg, Mississippi, 14-16 January 1969.

The laboratory tests and the analysis procedures described herein were developed in conjunction with research on propagation of ground shock through earth media being conducted by personnel of the Soils Division, WES, for DASA.

This report was prepared and presented by Mr. J. G. Jackson, Jr., Chief, Impulse Loads Section, Soil Dynamics Branch, Soils Division, WES. Mr. R. W. Cunny was Chief of the Soil Dynamics Branch and Mr. A. A. Maxwell was Acting Chief of the Soils Division during the preparation and publication of this report. Director of the WES was COL Levi A. Brown, CE; Technical Directors were Messrs. J. B. Tiffany and F. R. Brown. 


\section{Contents}

$\underline{\text { Page }}$

Foreword ....................... iii

Conversion Factors, British to Metric Units of Measurement . . . . vii

Summary. . . . . . . . . . . . . . . . . . ix

Introduction . . . . . . . . . . . . . . . . . 1

Basic Constitutive Relation and Typical Property Requirements. . . . 2

Equations and Assumptions Used for Analyses of Laboratory Tests. . . 3

Stress and strain components. . . . . . . . . . . 4

General equations for axial symmetry. . . . . . . . . 4

Assumptions .................... 5

Laboratory Test Data Available . . . . . . . . . . . 6

Uniaxial strain test. . . . . . . . . . . . . 6

Triaxial shear tests............... 8

Derivation of Constitutive Properties. . . . . . . . . . 9

Selection of site profile ................ 9

Selection of representative data for each type test . . . . 10

Construction of property relations. . . . . . . . . . . 14

Conclusion ...................... . . . 24 24

Literature Cited . . . . . . . . . . . . . . 27

Tables $1-4$ 
Conversion Factors, British to Metric Units of Measurement

British units of measurement used in this report can be converted to metric units as follows:

Multiply

feet

pounds per square inch

pounds per cubic foot

$\frac{\text { By }}{0.3048}$
0.070307
16.0185

To Obtain

meters

kilograms per square centimeter kilograms per cubic meter 


\section{Summary}

Computer codes used in the solution of free-field ground shock problems are based on mathematically defined constitutive models. Quantitative input for these constitutive models is primarily based on laboratory test data, but extensive anlalysis and numerous assumptions are required to convert these data to a form suitable for actual code input.

This report presents a detailed illustration of the analyses involved in deriving the soil constitutive properties required for a specific code formulation using laboratory test data from just one stratum of a single site. Data are available from static and dynamic uniaxial strain and triaxial shear tests; code property requirements are for mathematical expressions relating mean pressure to volumetric strain, Poisson's ratio to mean pressure, and a plastic yield criterion to mean pressure.

The illustration indicates that progress is being made in developing mathematical constitutive models that are realistic in terms of actual physical behavior, but that if many of the assumptions presently being made in soil property analyses are to be eliminated, additional soil tests and measurements must be developed. The illustration also raises questions as to the validity of models based on a constant Poisson's ratio or a constant shear modulus and suggests that the behavior of the various models be carefull, examined under different states and paths of stress. 


\section{Introduction}

1. The primary work of the U. S. Army Engineer Waterways Experiment Station (WES) Soil Dynamics Branch for the Defense Atomic Support Agency (DASA) has been in developing soil testing facilities and in conducting experimental and analytical investigations aimed at improving both the input and the mathematical formulation of constitutive relations used in free-field ground shock calculations. This is an area of considerable current interest to many, as numerous site investigations that require the most up-to-date constitutive property definitions and computational techniques are now in progress.

2. Last year (1968) laboratory test data from several sites were presented to qualitatively illustrate the effects of factors such as loading rate, stress history, degree of saturation, weathering, and state-ofstress on the stress-strain and strength properties generally used in various constitutive property formulations. ${ }^{1,2}$ The analyses involved in deriving the soil constitutive properties required for a specific code formulation will be quantitatively illustrated herein with laboratory test data taken from just one stratum of a single site. It is hoped that this will permit a better appreciation of the uncertainties and assumptions involved in such analyses and some insight into the research work that remains to be done.

3. Before getting into details, it should be pointed out that the particular laboratory tests and constitutive model that will be used in the illustration are not necessarily the most recent innovations. There are, as would be expected in an active research program, other tests and other constitutive models in various stages of development and evaluation. But the tests and model that will be used in the illustration presented herein do represent the current state-of-the-art, or what is now available for immediate application. 
4. The basic constitutive relation used to define stress-strain behavior utilizes the classical linear elastic relation between the stress tensor and the strain tensor and a yield criterion

$$
\sigma_{i j}=K e \delta_{i j}+2 G\left(\epsilon_{i j}-\frac{1}{3} e \delta_{i j}\right) \text { and } \sqrt{J_{\max }^{\prime}}=f(p)
$$

where

$$
\begin{aligned}
\sigma_{i j} & =\text { total stress tensor }=p \delta_{i j}+\sigma_{i j}^{\prime} \\
\epsilon_{i j} & =\text { total strain tensor }=\frac{1}{3} e_{i j}+\epsilon_{i j}^{\prime} \\
\delta_{i j} & =\text { Kronecker delta function } \\
\sigma_{i j}^{\prime} & =\text { deviator stress tensor } \\
\epsilon_{i j}^{\prime} & =\text { deviator strain tensor } \\
p & =\text { mean normal stress }=\frac{1}{3} \sigma_{k k} \\
e & =\text { volumetric strain }=\epsilon_{k k} \\
K & =\text { bulk modulus }=\frac{d p}{d e} \\
G & =\text { shear modulus }=\frac{1}{2} \frac{\sigma_{i j}^{\prime}}{\epsilon_{i j}^{\prime}} \\
J_{2}^{\prime} & =\text { second invariant of stress deviation }=\frac{1}{2} \sigma_{i j}^{\prime} \sigma_{i j}^{\prime}
\end{aligned}
$$

The constitutive model can be nonlinearized by using incremental stressstrain relations and defining one or both of the soil property coefficients $K$ and $G$ as functions of one of the stress or strain invariants such as $p$ or $e$. Inelasticity can be incorporated by programming two sets of property coefficient functions, one for use during virgin loading and one for use during unloading or reloading.

5. Soil property input to a computer code employing this basic constitutive model can be specified in a variety of forms. One typical set of constitutive property requirements consists of (a) hydrostat expressions relating mean pressure and volumetric strain for both loading and unloadingreloading, (b) a companion set of expressions for Poisson's ratio $\nu$ as 
a function of pressure, and (c) a yield criterion also as a function of pressure, or

$$
\begin{aligned}
p_{I} & =f_{I}(e) \text { and } p_{U}=f_{2}\left(e, e_{\max }\right) \\
\nu_{L} & =f_{3}(p) \text { and } \nu_{U}=f_{4}\left(p, p_{\max }\right) \text { where } \nu=\frac{3 K-2 G}{2(3 K+G)} \\
\sqrt{J_{\text {max }}^{\prime}} & =f_{5}(p)
\end{aligned}
$$

6. The unloading-reloading expressions must actually define families of equations that are dependent on previous stress or strain history. To generate these families, the current codes accept as input an expression for a single unloading-reloading curve and then apply a single-axis translation to the various points of unloading, specified as either $e_{\max }$ or $\mathrm{p}_{\max }$ - To prevent the model from developing energy-generating hysteresis loops due to this type translation, it must be required that, at any given pressure, the unloading bulk modulus be equal to or greater than the virgin loading modulus, or

$$
\frac{d p_{U}}{d e} \geq \frac{d p_{L}}{d e}
$$

\section{Equations and Assumptions Used for Analyses of Laboratory Tests}

7. In order that meaningful soil property definitions of the type just described can be obtained from the results of laboratory tests, the tests must be conducted under rigidly controlled states of stress for which all components of the stress and strain tensors can be defined, by measurement, by imposed boundary conditions, or by assumption. Before the various applied loadings, boundary conditions, and measurements applicable to the specific tests conducted in the WES laboratory are outlined, the general equations and assumptions used in the analyses of the data from all of the laboratory tests should be examined. 
8. Total stresses within the soil mass beneath the site being investigated are composed of initial geostatic or overburden stresses and live stresses induced by the blast loading, or

$$
\sigma_{\text {TOTAL }}=\sigma_{\text {OVERBURDEN }}+\sigma_{\text {LIVE }} \text { where } \sigma_{\text {TOTAL }} \geq 0
$$

It is generally assumed that the soil mass cannot support tension stresses, as indicated by the condition that the total stresses must always be equal to or greater than zero. Iote that this does not mean that live tension stresses cannot be supported; they can be supported up to the magnitudes of the overburden stresses, which increase continuously with depth. Reasonable estimates can be made for the magnitudes of these overburden stresses, which permits the setting of tension limits for the live stress components. Since the overburden stresses are relieved when the soil sample is removed from the ground, the test specimens must be statically recompressed under the estimated overburden pressure prior to application of the simulated live loading.

9. Total strains also consist of overburden and live components. But, unlike the case with stresses, overburden strains $\varepsilon_{0}$ cannot be readily estimated and, for all practical purposes, are indeterminate, or

$$
\epsilon_{\text {TOTAL }}=\varepsilon_{\text {OVERBURDEN }}+\epsilon_{\text {LIVE }} \text { where } \varepsilon_{0} \text { is indeterminate }
$$

Therefore, all WES laboratory stress-strain and strength results and the constitutive relations derived from them are given in terms of live stress and live strain. This means that the zero position on the axes of the various plots is assumed to represent the position of the specimen in situ, and the plots themselves depict response of the specimen to applied live loadings or departures from the original in situ stress condition. General equations for axial symmetry

10. The laboratory tests currently used for WES soil property investigations are all axially symmetric so the specimens can be analyzed in 
terms of cylindrical coordinates using the two general equations of equilibrium

$$
\begin{gathered}
\frac{\partial \sigma_{r}}{\partial r}+\frac{\partial \sigma_{r z}}{\partial z}+\left(\frac{\sigma_{r}-\sigma_{\theta}}{r}\right)=\rho \frac{\partial^{2} u}{\partial t^{2}} \\
\frac{\partial \sigma_{r z}}{\partial r}+\frac{\partial \sigma_{z}}{\partial z}+\frac{\sigma_{r z}}{r}-\gamma=\rho \frac{\partial^{2} w}{\partial t^{2}}
\end{gathered}
$$

and the four strain-displacement relations

$$
\epsilon_{r}=\frac{\partial u}{\partial r}, \epsilon_{\theta}=\frac{u}{r}, \varepsilon_{z}=\frac{\partial w}{\partial z}, \epsilon_{r z}=\frac{l}{2}\left(\frac{\partial u}{\partial z}+\frac{\partial w}{\partial r}\right)
$$

provided that a few assumptions are made.

\section{Assumptions}

11. First, it is assumed that the inertia stresses of the specimen are negligible, which allows the acceleration terms $\rho \frac{\partial^{2} u}{\partial t^{2}}$ and $\rho \frac{\partial^{2} w}{\partial t^{2}}$ to be dropped. Insofar as possible, this condition is ensured by controlling the loading rise times in the experiments. Next, the gravity stresses due to the weight of the relatively small test specimens are considered negligible, which allows the $\gamma$ term to be dropped; but, as was pointed out earlier, the total gravity or overburden stresses acting on the specimen are not negligible and must be applied as part of the boundary loading.

12. It is also assumed that all shear stresses and all shear strains are negligible, which permits all $\sigma_{r z}$ and $\epsilon_{r z}$ terms to be dropped. Ensuring this condition is attempted by sealing the specimens and applying the boundary loading through fluids wherever possible. Having thus eliminated all but the $\frac{\partial \sigma_{z}}{\partial z}$ term in the second equilibrium equation, it must be zero, which implies that a uniform state of vertical stress exists within the specimen.

13. Having established one condition of uniform stress, it is simply assumed that all other states of stress and all states of strain are 
uniform within the specimen. This leads to the conclusion that $\frac{\partial \sigma_{r}}{\partial r}=0$ and hence, from the first equilibrium equation, that $\frac{\sigma_{r}-\sigma_{\theta}}{r}=0$ or that $\sigma_{r}=\sigma_{\theta}$. The assumption of a uniform state of strain means that $\frac{\partial u}{\partial r}=\frac{u}{r}$ or that $\varepsilon_{r}=\varepsilon_{\theta} \cdot 3$ Mean pressure and volumetric strain for the tests are therefore defined as

$$
\begin{aligned}
& p=\frac{1}{3}\left(\sigma_{z}+2 \sigma_{r}\right) \\
& e=\left(\varepsilon_{z}+2 \epsilon_{r}\right)
\end{aligned}
$$

\section{Laboratory Test Data Available}

14. The laboratory data for constitutive property analyses are obtained from two basic tests, i.e., the uniaxial strain and the triaxial shear tests. A brief outline of the boundary and loading conditions, measured responses, and the types of data plots generally obtained from these tests follows. Details regarding equipment and test techniques are given in references $4,5,6$, and 7 .

Uniaxial strain test

15. In the uniaxial strain test (see fig. 1) a condition of zero radial strain is imposed as a boundary restraint on the specimen while a controlled vertical stress is applied to it. The response of the specimen is measured in terms of a vertical surface displacement $\Delta L$, which is converted to Lagrangian vertical strain $\varepsilon_{z}$ by dividing, the displacement time history by the original height of the specimen. Since the radial strain is zero, the vertical strain determined from the uniaxial strain test also defines volumetric strain e. Instantaneous or Eulerian volumetric strain can be obtained from

$$
\mathrm{e}=\frac{\Delta \mathrm{V}}{\mathrm{V}}=\frac{\varepsilon_{\mathrm{z}}}{I-\varepsilon_{\mathrm{z}}}
$$

Plots of $\sigma_{z}$ as a function of $\varepsilon_{z}$ are the primary end product; the slopes of these curves define the constrained modulus $M$. The constrained 
BOUNDARY AND LOADING CONDITIONS

$\epsilon_{r}=\frac{\Delta R}{R}=0$

$\sigma_{2}(t)$
APPLIED AND

MEASURED

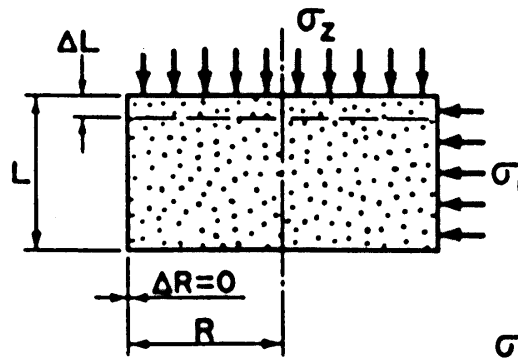

MEASURED RESPONSES

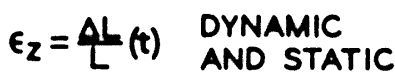

$\sigma_{r}$

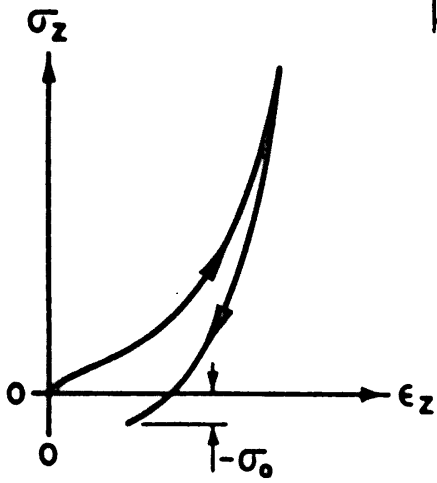

$M=\frac{\Delta \sigma_{z}}{\Delta \epsilon_{2}}=\frac{3 k(1-\gamma)}{(1+v)}$

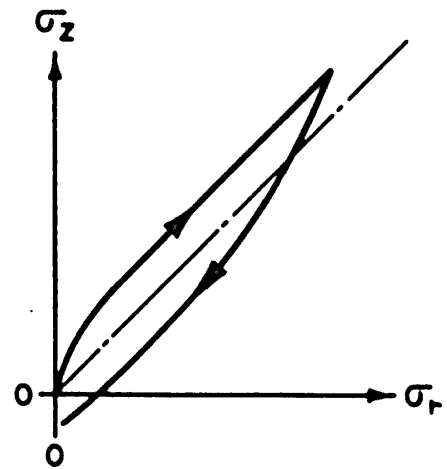

Fig. 1. Data available from uniaxial strain test

modulus is related to the bulk modulus $K$ and Poisson's ratio $\nu$ needed for the constitutive model, but does not define either explicitly.

16. When the specimen is unloaded, all stress (including both the live stress and the overburden prestress) is removed dynamically. This permits measurement of the response of the specimen to live tension stresses up to the limit set by the overburden as shown in fig. 1. By including this negative portion of the unloading curve in the constitutive property formulation, the necessity for including a gravity term in the equations of motion for the code is considered to have-been eliminated, which, if correct, should simplify the computational scheme.

17. Although its measurement is difficult, the radial stress required to maintain a condition of zero radial strain can often be measured during static uniaxial strain tests. Such a measurement then permits plotting $\sigma_{z}$ as a function of $\sigma_{r}$. These plots are most useful in that from them, Poisson's ratio, mean pressure, and the square root of the second invariant of stress deviation can be calculated directly, since for the condition of uniaxial strain 


$$
\nu=\frac{\Delta \sigma_{r}}{\Delta \sigma_{z}+\Delta \sigma_{r}}, p=\frac{\sigma_{z}+2 \sigma_{r}}{3}, \quad \sqrt{J_{2}^{\prime}}=\frac{\sigma_{z}-\sigma_{r}}{\sqrt{3}}
$$

Triaxial shear tests

18. In the triaxial shear test (see fig. 2), a constant all-around stress $\sigma_{c}$ is first imnosnd on the specimen. Then while this stress is maintained as a boundar: condition in the radial direction (i.e., $\sigma_{r}=$ $\sigma_{c}=$ constant), either controlled axial deformation rates $\frac{\Delta \mathrm{L}}{\Delta t}$ or controlled axial stresses $\sigma_{a}$ are applied until the specimen fails in shear. The response of the specimen is measured, either as a vertical strain for the controlled stress tests or as an axial deviator stress (or principal stress difference) for the controlled deformation tests. Tests can be conducted both dynamically and statically; the maximum radial stress currently used with dynamic tests is 300 psi,* but static tests can be conducted with radial stresses up to 10,000 psi.

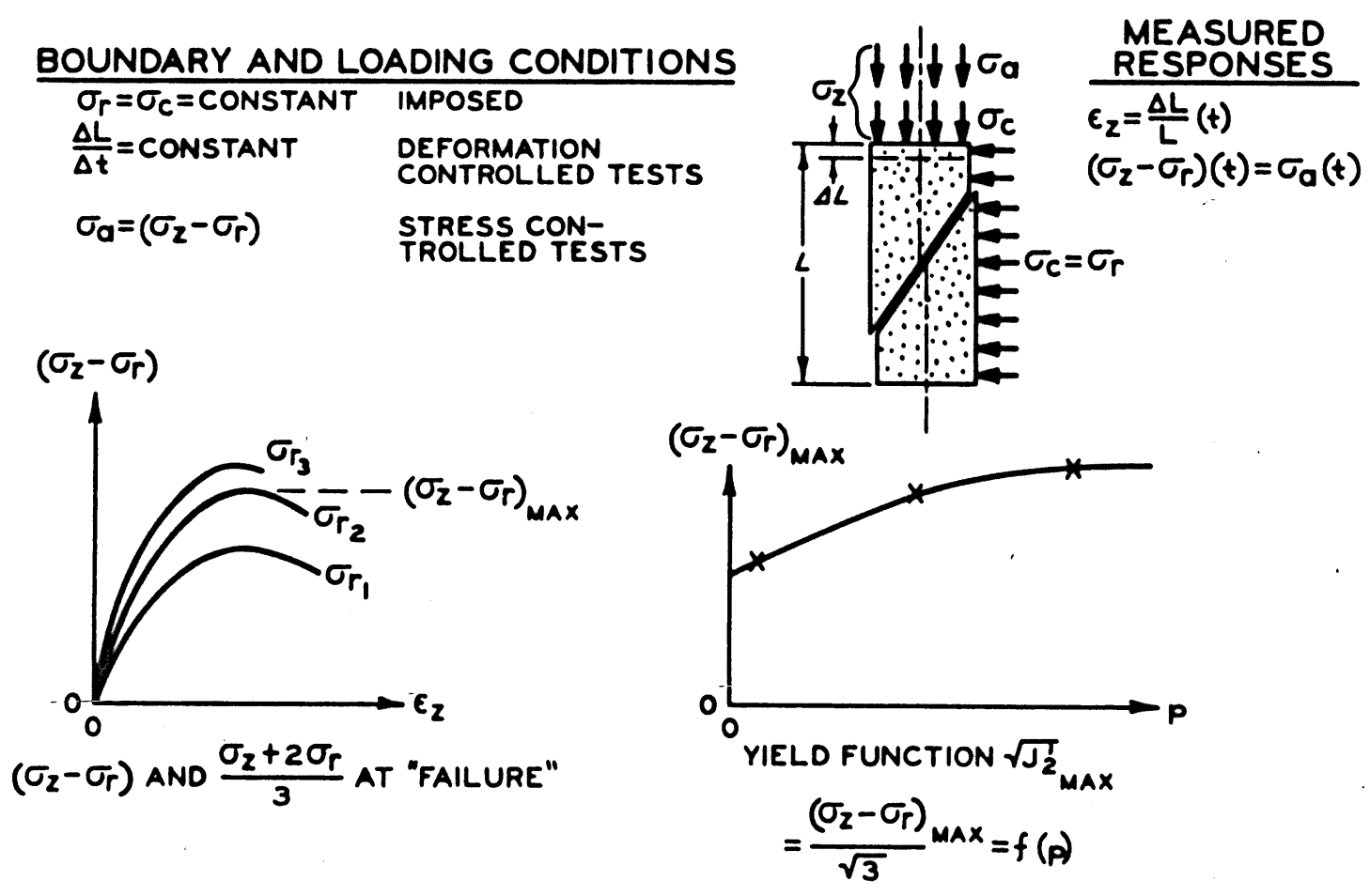

Fig. 2. Data available from triaxial shear tests

* I table of factors for converting British units of measurement to metric units is presented on page vii. 
19. In either case, the primary product is a plot of principal stress difference versus vertical strain as shown in fig. 2. Only the stress information at "failure" or $\left(\sigma_{z}-\sigma_{r}\right)_{\max }$ as a function of $\sigma_{r}$ is currently used; these data are used to plot an envelope of maximum principal stress difference versus pressure. Such an envelope is directly proportional to the yield function $\sqrt{J_{2}^{\prime}}$.

\section{Derivation of Constitutive Properties}

20. It is significant to note that although the uniaxial strain and triaxial shear tests yield some obviously useful stress-strain and strength property information, neither of them directly yields the specific properties outlined in paragraph 5 as required input for the constitutive model. It is, therefore, appropriate now to go through the steps involved in deriving, from laboratory test data of the type just described, a complete set of constitutive properties in a form suitable for code input. Selection of site profile

21. One of the first steps is the selection of a typical site profile. No two boring logs are ever exactly alike; but since the ground shock codes are presently only two-dimensional, a single boring profile. has to be constructed that is assumed to be most representative of the area to be included in the calculation. Of course, the more borings available for such an analysis, the better.

22. The soil profile shown in fig. 3 came from a site near Valley City, North Dakota. As can be seen in fig. 3, the profile is made up of graphic symbols and word descriptions that are used as guides to divide the site into layers or zones; a set of meaningful constitutive properties must then be defined for each zone selected. Selection of the layers obviously has to be coordinated with the ground shock calculator, since the number of layers and the minimum layer thickness are functions of the code, the computer available, and the time step to be used.

23. For example purposes, a 10-ft-thick zone from a depth of 45 to 55 ft below the ground surface was selected. The blowup of this zone in fig. 3 shows the location of various laboratory test specimens within the 

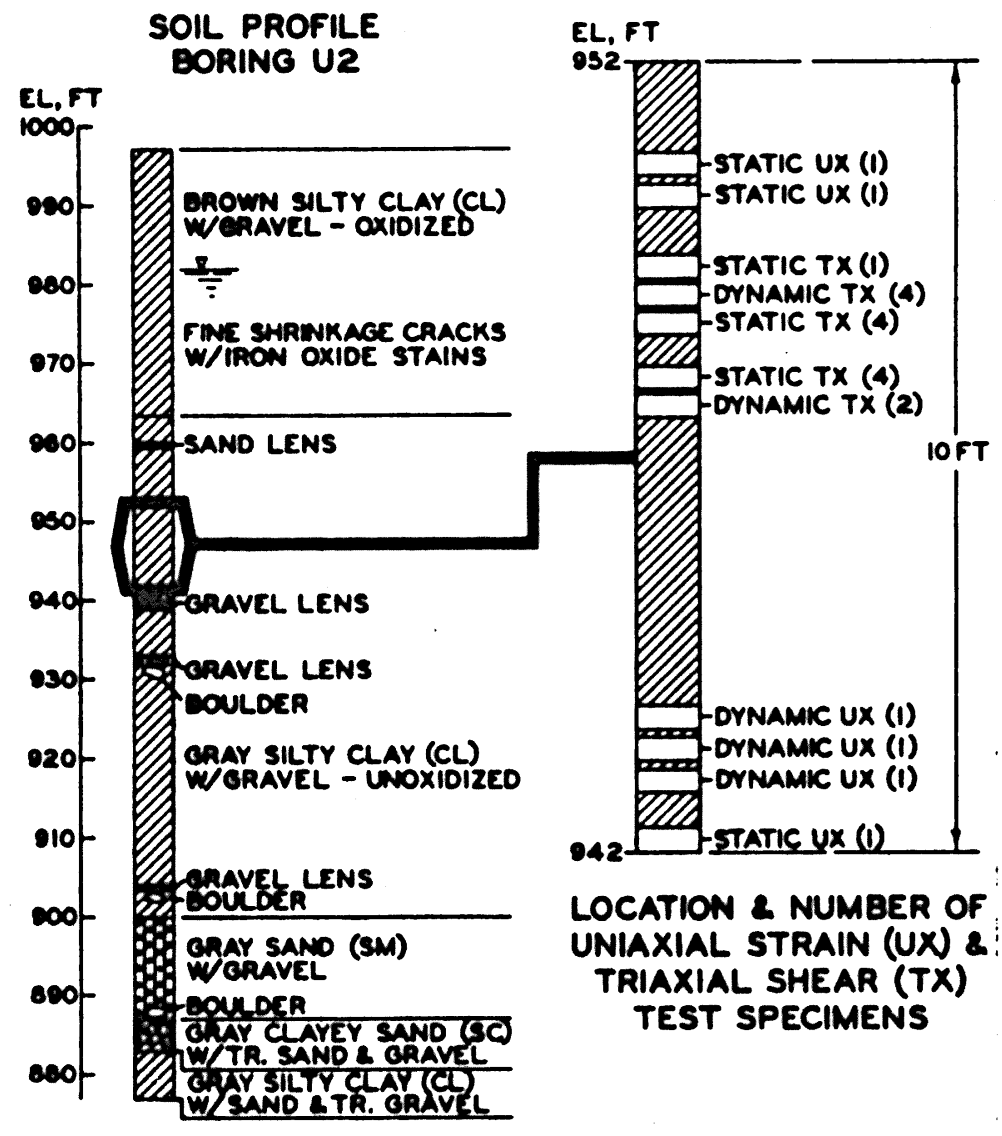

Fig. 3. Soil profile and test specimens used in analyses zone. For the example analysis, there are results from three dynamic uniaxial strain tests, three static uniaxial strain tests with radial stress measurements, six dynamic triaxial shear tests, and nine static triaxial shear tests.

Selection of representative data for each type test

24. The next step is to select representative data from this layer for each type test. This is by far the most important step and should be much more than a simple quantitative averaging of the test

results. Every possible check should be made to ensure that the selections represent logical conclusions that are consistent with other available data and at least with the more basic principles of soil mechanics.

25. Results of the three dynamic uniaxial strain tests are shown in fig. 4; the curve shown by the dashed line is considered to be the most representative dynamic uniaxial strain response for the entire 10-ft-thick layer. Also shown are the average composition properties of water content $w$, dry unit weight $\gamma_{d}$, specific gravity of soil solids $G_{s}$, void ratio c , percent saturation $\mathrm{S}$, and the percentages by volume of air $\mathrm{V}_{\mathrm{a}}$, water $\mathrm{V}_{\mathrm{w}}$, and solids $\mathrm{V}_{\mathrm{S}}$.

26. The individual test specimens were, on the average, 99.3 percent saturated and contained 0.3 percent air by volume. These properties refer 
to the composition of the specimens after the static overburden stress has been reapplied; prior to this loading the specimens in the laboratory were, on the average, only 97.3 percent saturated. This 2.0 percent increase in saturation can be accounted for by compression and solution of free air caused by larger pore water stresses in the in situ condition than those existing in the specimen upon its removal from the ground. The relation between in situ degree of saturation and its value at the surface is given by the following equation: 8

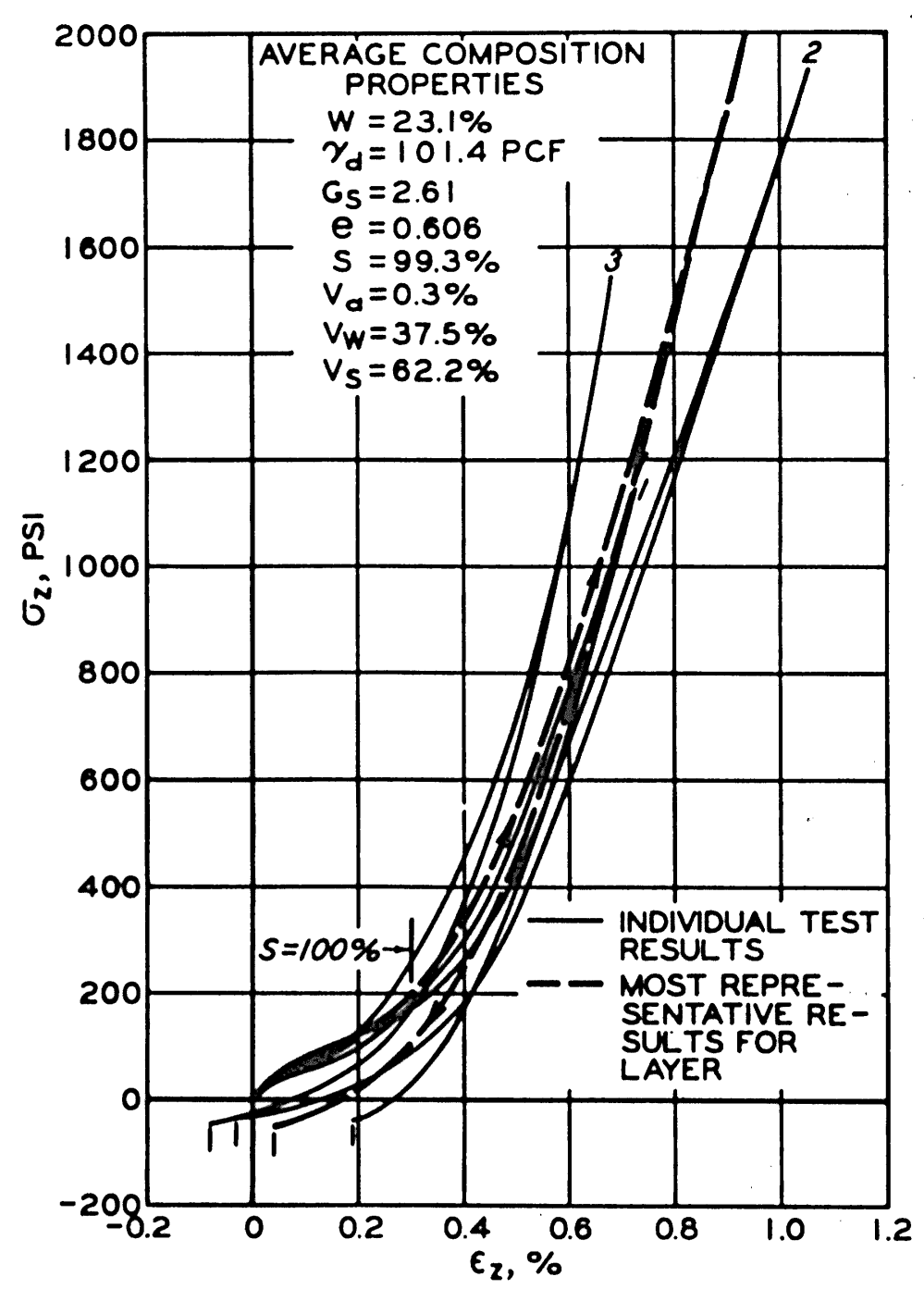

Fig. 4. Dynamic uniaxial strain test results

$$
S=\frac{\left(I+\frac{u}{u_{a}}\right) S_{0}}{I+\frac{u}{u_{a}}(I-h) S_{0}}
$$

where

$\mathrm{S}=$ in situ degree of saturation (or saturation as determined from laboratory tests after application of overburden simulating preload $=0.993$ )

$\mathrm{S}_{\mathrm{O}}=$ degree of saturation at ground surface (or saturation as determined from laboratory tests prior to application of overburden simulating preload $=0.973$ )

$u=$ in situ pore water pressure (gage pressure) 
$u_{a}=$ atmospheric pressure $=14.7$ psi

$\mathrm{h}=$ gas solubility constant (0.02 for air)

Substitution in the above equation shows that the increased saturation is associated with a pore water pressure $u$ increase of approximately 13 psi; a pore pressure increase of this magnitude would require that the specimens be located at least $30 \mathrm{ft}$ below the free water table. This is in good agreement with the field data and suggests that the specimen compositions in the laboratory prior to live load application are reasonably representative of those of the in situ specimens.

27. Assuming that the initial live strain also represents air being forced into solution, 100 percent saturation would occur at a live vertical strain of 0.3 percent or at a live vertical stress of $200 \mathrm{psi}$, as shown in fig. 4. This result is also quite reasonable since the curves show a definite stiffening effect at that point, which is characteristic of saturation. 2,9

28. For this example, the representative dynamic uniaxial strain relation has been defined to a maximum vertical stress of 2000 psi. This cannot be a purely arbitrary decision on the part of the soils engineer, but must be worked out in advance with the calculator based on the maximum pressure to be input at the starting ground range and preliminary estimates of stress attenuation with depth.

29. Results of the three static uniaxial strain tests, with radial stress as well as vertical strain measurements, are given in fig. 5. Data for these tests were available up to a vertical stress of only about $350 \mathrm{psi}$. The most representative relations between $\sigma_{z}$ and $\epsilon_{z}$ and between $\sigma_{z}$ and $\sigma_{r}$ are defined by the dashed lines. According to the specimen composition data shown in fig. 4, 100 percent saturation should occur at a strain of 0.3 percent or at a vertical stress of about 35 psi and a radial stress of about $20 \mathrm{psi}$; this is equivalent to a mean pressure of only 25 psi. For the dynamic tests, the vertical stress required for full saturation was $200 \mathrm{psi}$ or an estimated mean pressure of about $150 \mathrm{psi}$.

30. Fig. 6 shows static triaxial shear test results for four controlled rate of deformation tests with $\sigma_{r}$ values up to $70 \mathrm{psi}$ and five controlled stress tests with $\sigma_{r}$ values up to $1470 \mathrm{psi}$. The maximum 

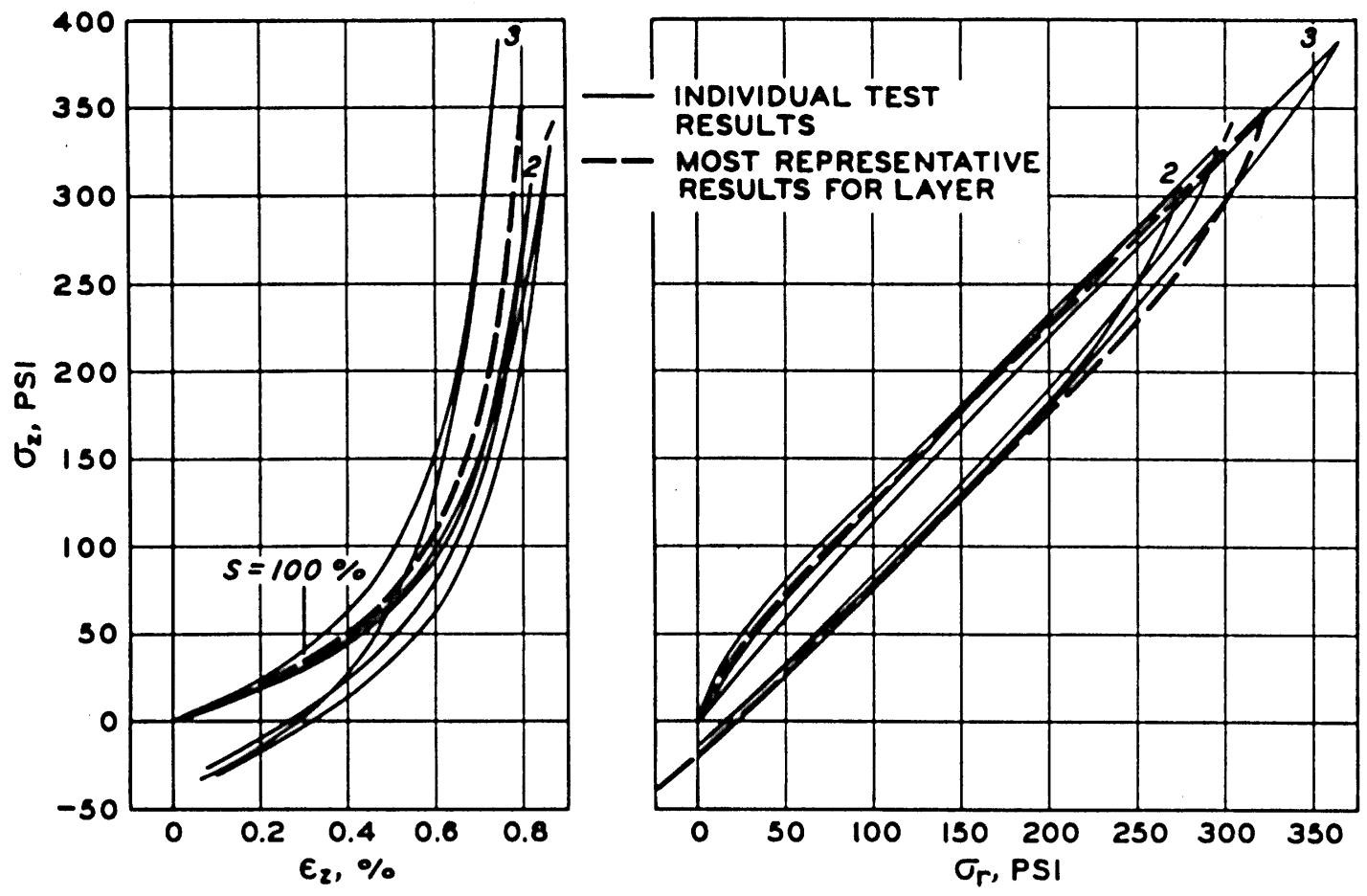

Fig. 5. Static uniaxial strain test results
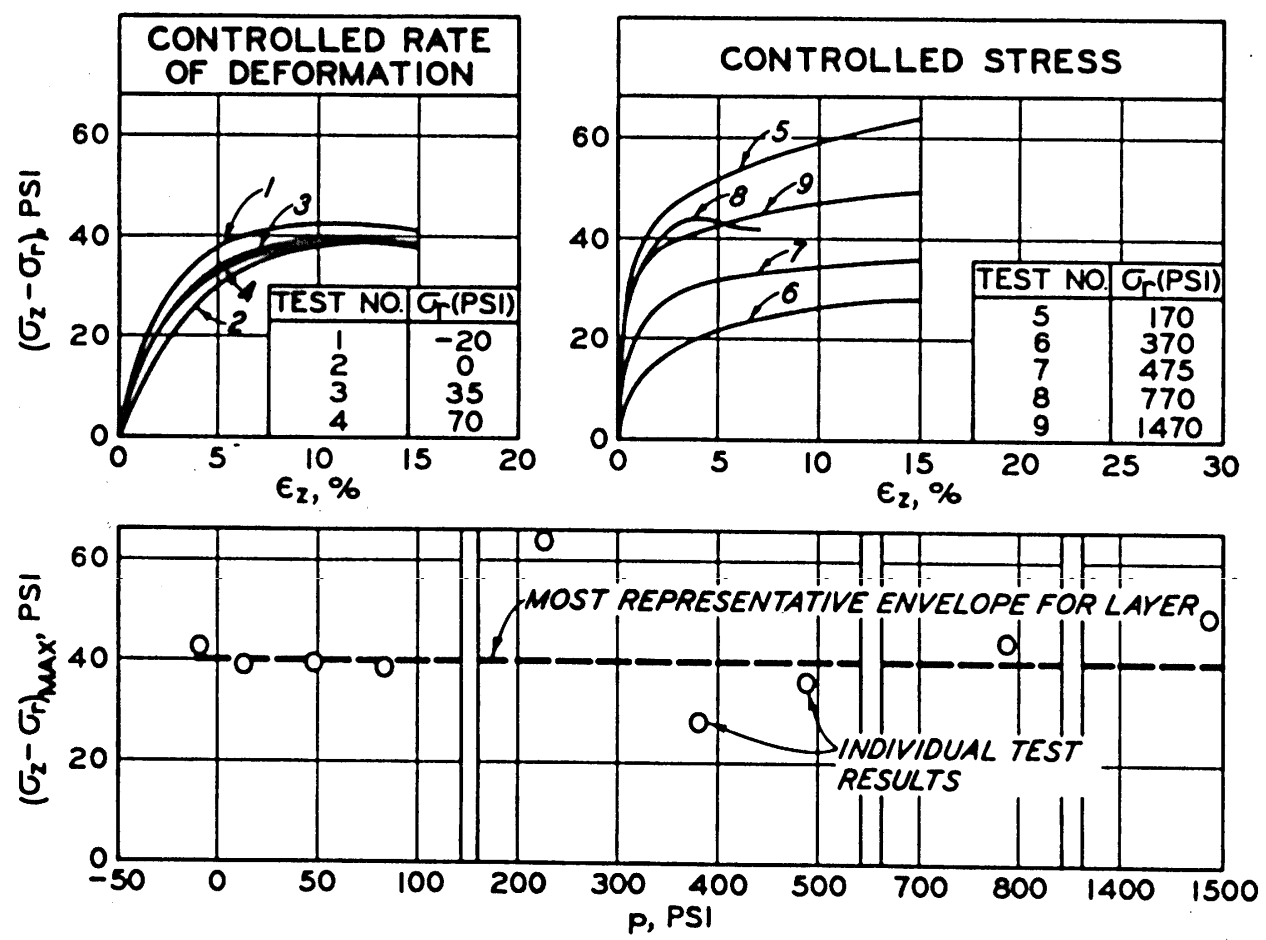

Fig. 6. Static triaxial shear test results 

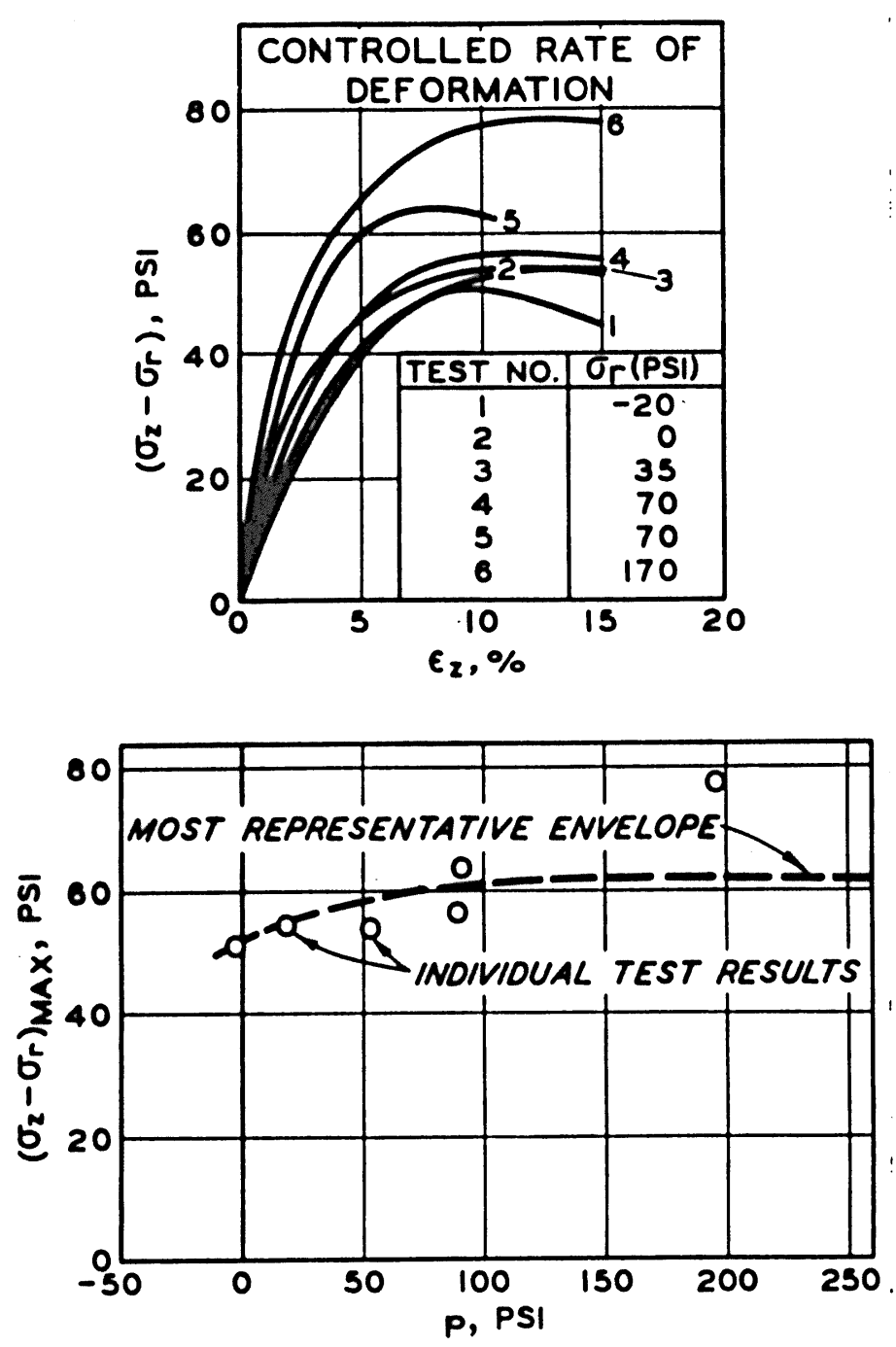

Fig. 7. Dynamic triaxial shear test results principal stress differences from these tests have been plotted as a function of mean pressure, and the most representative static failure envelope was drawn for the layer. Note that the envelope is flat, or of the von Mises type, through its entire pressure range. This indicates that saturation occurred at a very low pressure, which is in agreement with the static uniaxial strain test data shown in fig. 5.

31. Fig. 7 shows the results from six dynamic triaxial shear tests conducted with radial stresses up to only $170 \mathrm{psi}$. The results with these relatively low $\sigma_{r}$ values indicate a gradual increase in maximum principal stress

difference with mean pressure, but the most representative envelope has been flattened at a pressure of about 150 psi since the dynamic uniaxial strain test results indicated 100 percent specimen saturation at that pressure. The maximum dynamic strength is 62 psi, which is 1.55 times the maximum static value of 40 psi shown in fig. 6 . Construction of property relations

32. After the representative test data have been selected, the final step is construction of the trirce constitutive property relations as outlined for computer infut: pressure versus volumetric strain functions, 
Poisson's ratio versus pressure functions, and a yield function.

33. The first to be determined is the yield function. A limiting principal stress difference versus pressure envelope from the static triaxial test results was defined (see fig. 6), but as noted in paragraph 17, principal stress difference versus pressure for a complete load-unload cycle can be calculated directly from the results of static uniaxial strain tests with radial stress measurements. The $\sigma_{z}$ versus $\sigma_{r}$ values from the plot given in fig. 5 as the most representative static uniaxial strain response for the layer have been converted to values of $\left(\sigma_{z}-\sigma_{r}\right)$ versus $\mathrm{p}$ in table 1 so that a comparison can be made with the static triaxial test results.

34. The comparison between the static uniaxial strain test relation for $\left(\sigma_{z}-\sigma_{r}\right)$ versus $p$ and the static triaxial shear test results is shown in fig. 8. The heavy solid line at a principal stress difference of $40 \mathrm{psi}$ is the representative triaxial shear envelope determined from the static test data; its mirror image is plotted at $-40 \mathrm{psi}$ as a limit for unloading. The other solid line is the path of principal stress difference

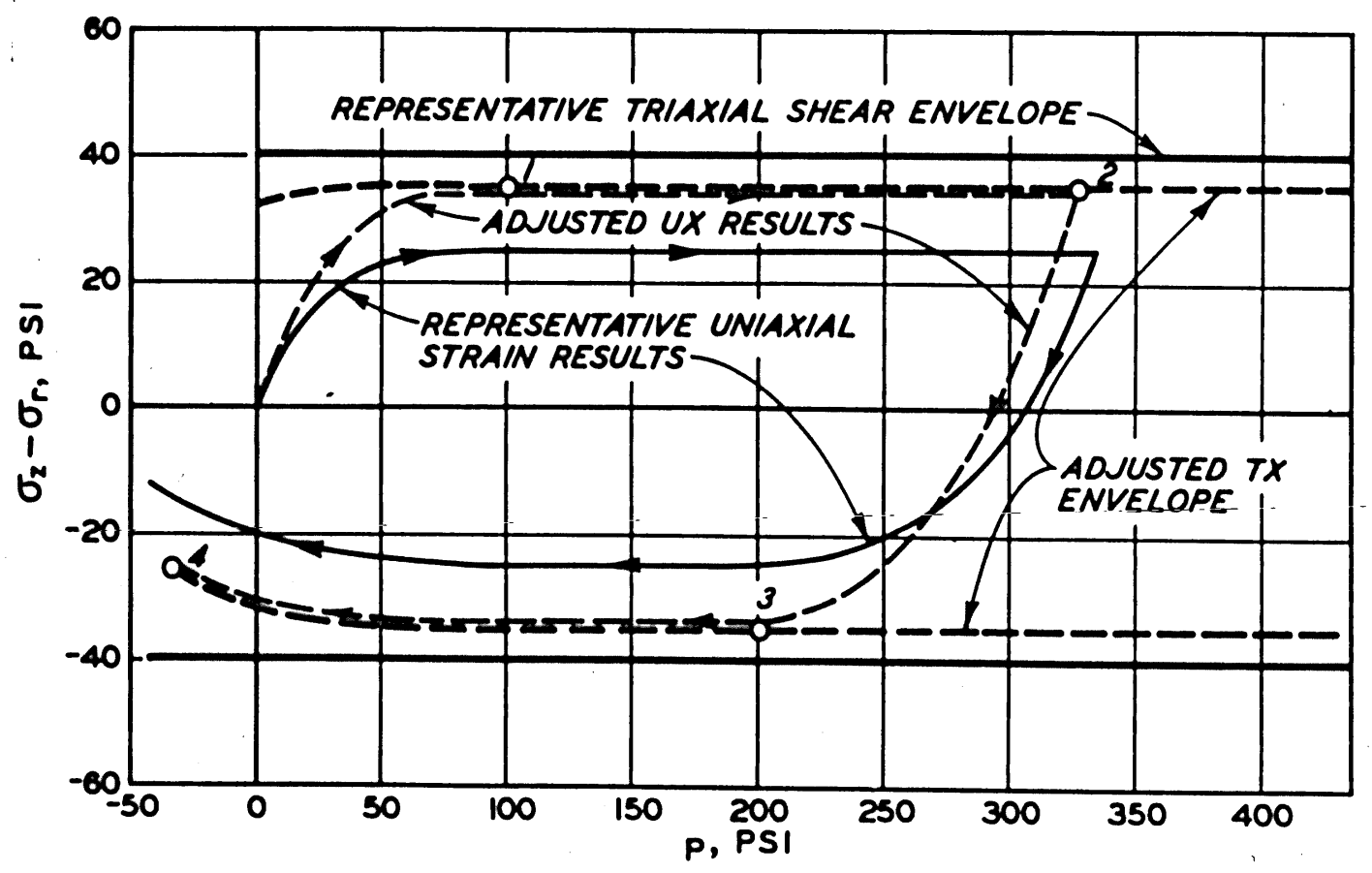

Fig. 8. Static uniaxial strain and triaxial shear results adjusted for compatibility 
versus pressure plotted from the static uniaxial strain results given in table 1. Note that a constant principal stress difference of 25 psi, or yield, is reached at a pressure of about 100 psi. Yielding continues until the maximum test pressure j.s reached; then the path abruptly leaves the upper yield surface on unloading, but appears to yield again along a lower yield surface after the pressure decreases to about 200 psi.

35. Since the triayial test data indicated a yield envelope with a maximum principal stress difference of $\pm 40 \mathrm{psi}$ and the uniaxial strain data gave $\pm 25 \mathrm{psi}$, some adjustrent had to be made to make them compatible. More weight was given to the triaxial test data in this case, and a maximum yield value of $35 \mathrm{psi}$ was selected. The heavy dashed line in fig. 8 represents the downward adjusted triaxial shear envelope and the lighter dashed line, the upward adjusted path of uniaxial strain. Both the loading yield pressure value of $100 \mathrm{psi}$, at point 1 , and the unloading value of $200 \mathrm{psi}$, at point 3, were retained. The pressure at point 2 is determined by the maximum vertical stress of $350 \mathrm{psi}$, and that at point 4 represents the limit for unloading set by the weight of the overburden as a vertical stress of -50 psi.

36. The static uniaxial strain and triaxial shear results have now been adjusted to be compatible with each other. The next step is to adjust the dynamic shear envelope to be compatible with the adjusted static shear envelope. The dashed line in fig. 9 is the static shear envelope that was adjusted downward from a naximum principal stress difference of $40 \mathrm{psi}$ to $35 \mathrm{psi}$. The dynamic envelope, shown by the solid line, has also been adjusted downward from a test-determined maximum principal stress difference value of $62 \mathrm{psi}$ to a new value of $55 \mathrm{psi}$ in order to preserve the 1.55 ratio between dynamic yield strength and static yield strength indicated by the laboratory tests.

37. The dynamic shear envelope for $\left(\sigma_{z}-\sigma_{r}\right)_{\max }$ as a function of $p$ has now been established for the constitutive model and can be readily fit sith a polynomial to Give a computer-acceptable equation for the dynamic yield relation as show in fig. 9 .

38. Next, a Poissun's ratio versus pressure relation is required. 


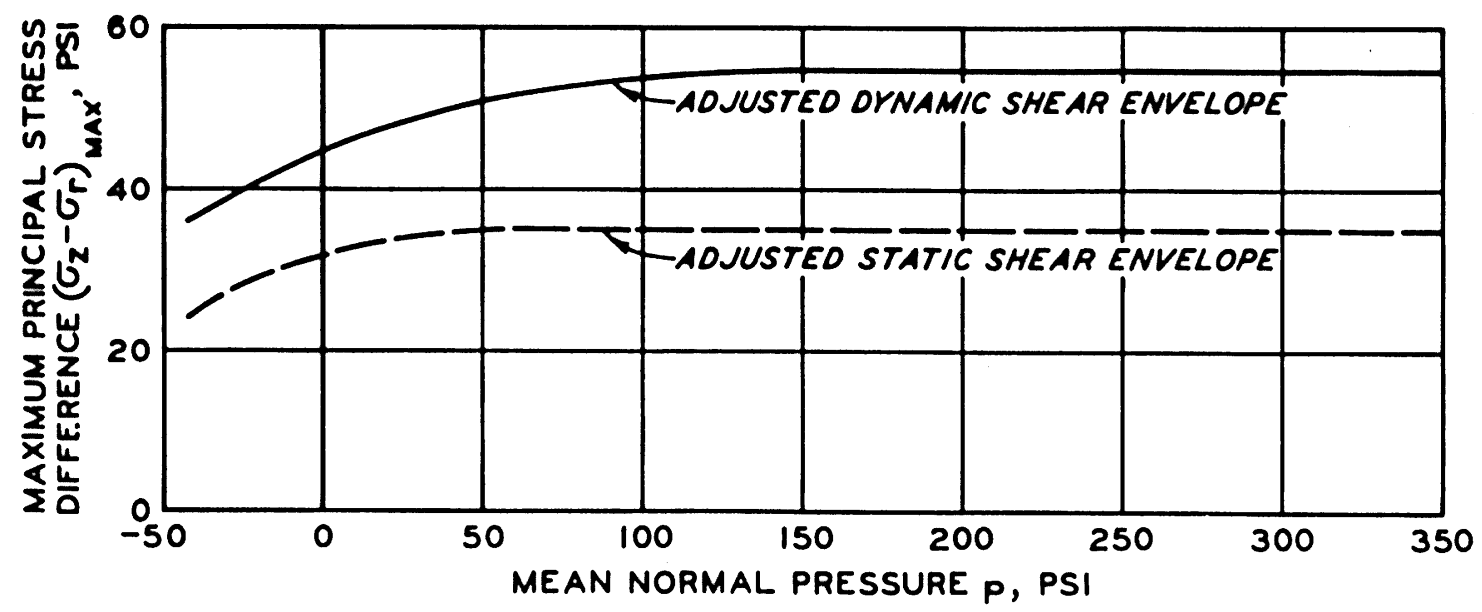

EQUATION FOR DYNAMIC YIELD RELATION

$$
\begin{array}{rlrl}
\sqrt{J_{2}^{\prime}}=\frac{\left(\sigma_{z A X}-\sigma_{r}\right)_{\text {MAX }}}{\sqrt{3}} & =25.8+0.0953 p-0.000370 p^{2} \text { FOR } p<150 \text { PSI } \\
& =31.8 & \text { FOR } p \geq 150 \text { PSI }
\end{array}
$$

Fig. 9. Adjusted dynamic shear envelope and yield equation

In order to get that, a path of principal stress difference versus pressure for dynamic uniaxial strain must be established to go with the adjusted dynamic shear or yield envelope. Since the necessary dynamic data for this stress path are not available, one has to be constructed based on static information. The heavy solid lines in fig. 10 represent the

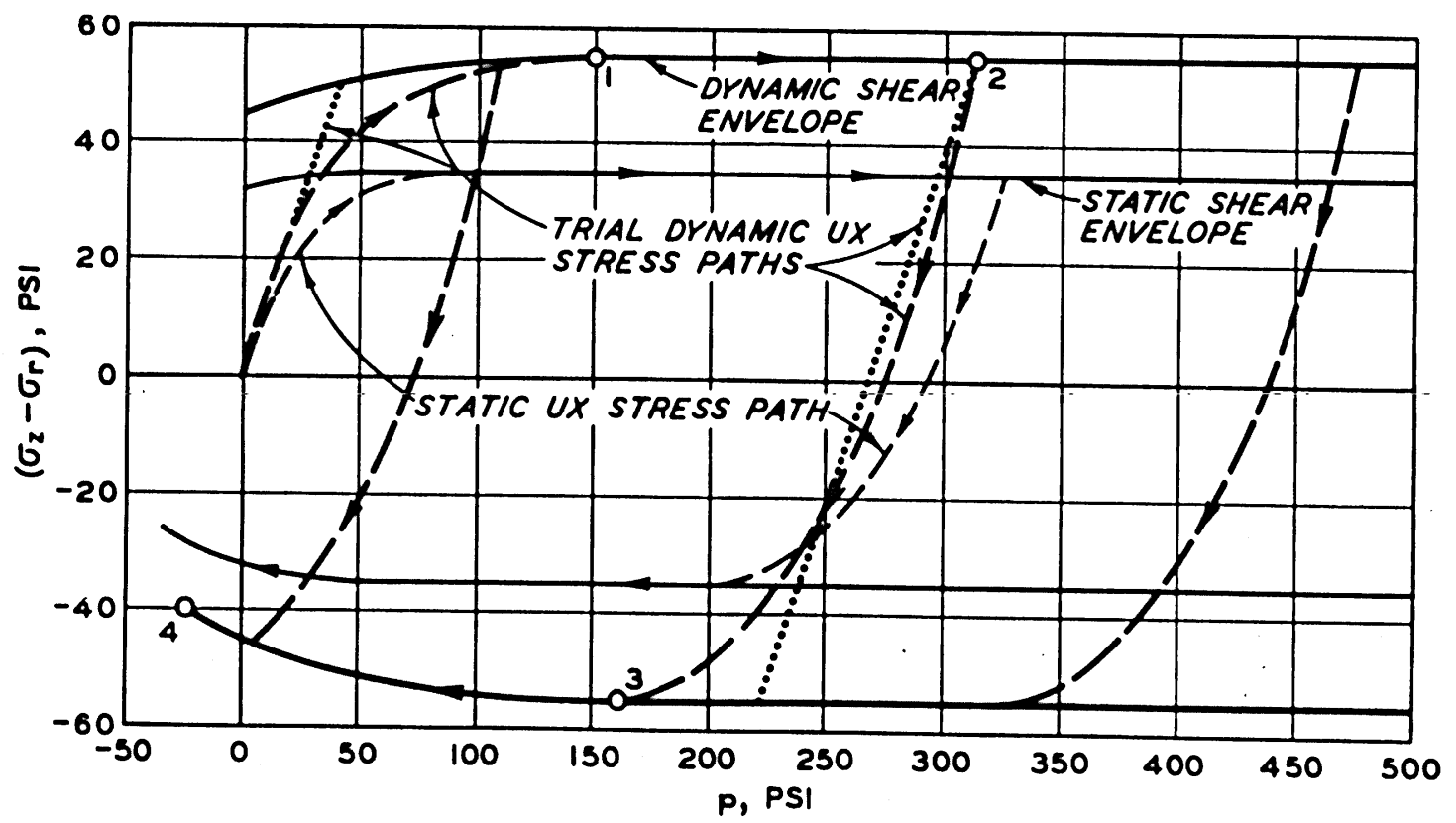

Fig. 10. Trial stress paths for dynamic uniaxial strain 
dynamic shear envelope and the lighter solid lines, the static shear envelope. The light dashed line shows the $\left(\sigma_{z}-\sigma_{r}\right)$ versus $p$ path for static uniaxial strain during loading to yield and unloading between yield surfaces. The slopes along this path are related to Poisson's ratio by the expression

$$
\frac{d\left(\sigma_{z}-\sigma_{r}\right)}{d p}=\frac{3(1-2 \nu)}{1+\nu}
$$

A slope of 3 represents a Poisson's ratio of zero, and a zero or horizontal slope represents a Poisson's ratio of 0.5 .

39. Experience has been that, although the static and dynamic soil test responses may be quantitatively different, they are quite similar in form as indicated by the results given in figs. 4, 5, 6, and 7. Thus, the first trial dynamic stress path of $\left(\sigma_{z}-\sigma_{r}\right)$ versus $p$ (shown by the heavy dashed line in fig. 10 between the origin and point $I$ and between points 2 and 3) was given a shape similar to the static path. With this path, Poisson's ratio continuously increases over a pressure range of 150 psi (based on the estimated dynamic uniaxial strain saturation pressure) during both loading and unloading. A much more simplified assumption is to let Poisson's ratio be constant. A second trial path was constructed for a constant Poisson's ratio of 0.25 as shown by the dotted lines in fig. 10.

40. Now, some assumption must be made about unloading from maximum pressures other than that associated with a vertical stress of 350 psi. The most logical guess would be a simple p-axis translation as indicated by the heavy dashed lines in fig. 10 constructed parallel to the one between points 2 and 3; such a translation is consistent with a constant Poisson's ratio or single-slope assumption.

41. Once two trial dynamic stress paths of principal stress difference versus pressure for a state of uniaxial strain have been established, they can readily be converted to more useful plots of $\sigma_{z}$ versus $\sigma_{r}$. The long-dashed line in fig. 11 shows the adjusted static uniaxial strain relation between $\sigma_{z}$ and $\sigma_{r}$. The solid line shows the first trial dynamic relation: point $I$ indicates the point of first yield during loading; point 2 corresponds to the maximum vertical stress of 350 psi; point 3 
represents first yield during unloading; and point 4 the limiting tension value of $\sigma_{z}=-50$ psi. The data for this trial dynamic stress path are given in table 2 . The short-dashed lines in fig. II show the second trial or idealized dynamic uniaxial strain relation corresponding to a constant Poisson's ratio of 0.25 .

42. Now that there are dynamic uniaxial strain values for $\sigma_{z}$ versus $\sigma_{r}$ as well as for $\sigma_{z}$ versus $\epsilon_{z}$, a curve of mean pressure $\mathrm{p}$ versus volumetric

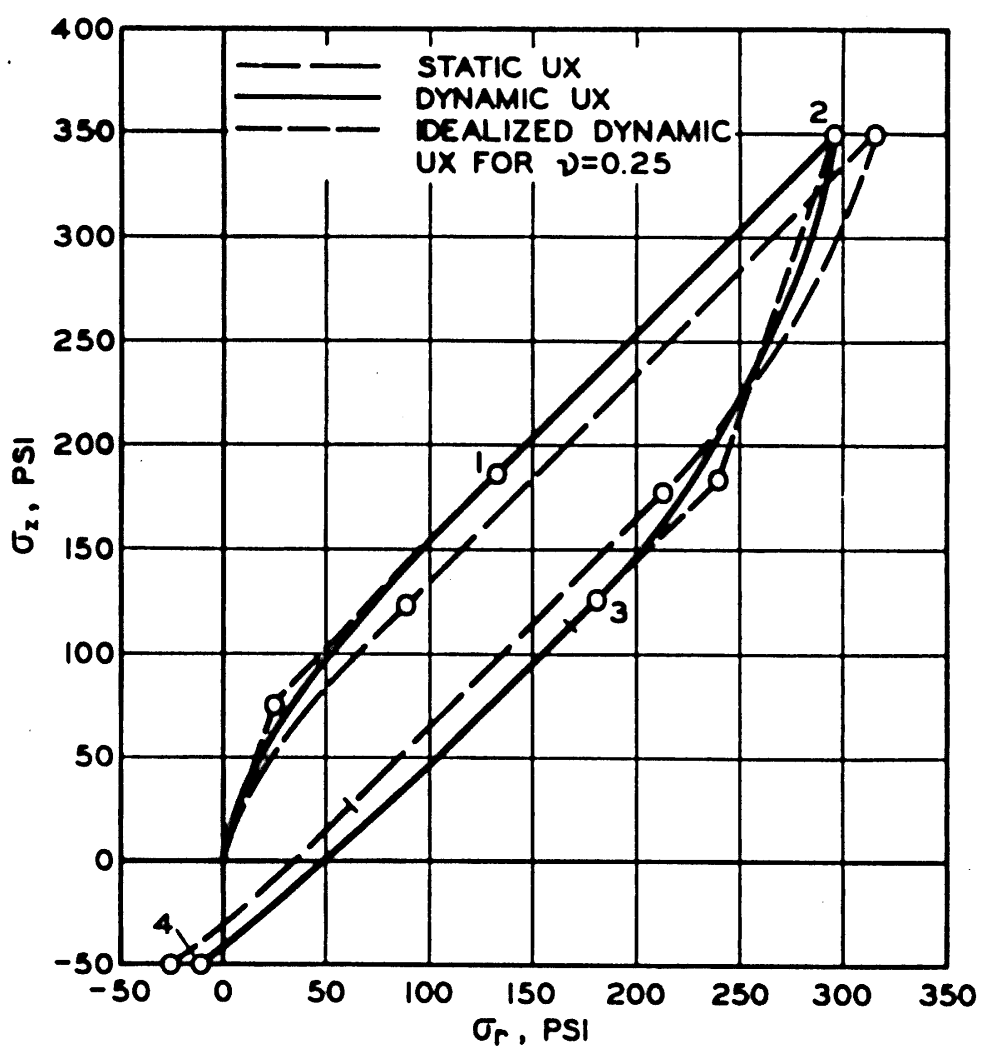

Fig. 11. Vertical stress versus radial stress for uniaxial strain based on trial stress paths

strain e can be plotted. But since the plot must extend to a vertical stress of $2000 \mathrm{psi}$, the $\sigma_{\mathrm{z}}$ versus $\sigma_{\mathrm{r}}$ relation to this maximum stress must first be extended according to the p-axis translation assumption. The tabulated data for this extended $\sigma_{z}$ versus $\sigma_{r}$ relation from the first trial dynamic uniaxial strain stress path and the corresponding $p$ versus e function are given in table 3. The light solid line in fig. 12 shows the $\sigma_{z}$ versus $\sigma_{r}$ relation, first unloaded from a $\sigma_{z}$ of 350 psi and then extended to a $\sigma_{z}$ of $2000 \mathrm{psi}$ and unloaded. The corresponding $p$ versus $e$ relation is shown by the heavy solid line.

43. This trial combination of $\sigma_{z}$ and $\sigma_{r}$ produces an interesting result in the $p$ versus $e$ relation at high pressure; the unloading volumetric strains are less than the loading strains. This portion of the data has been plotted on an expanded scale in the upper left-hand 


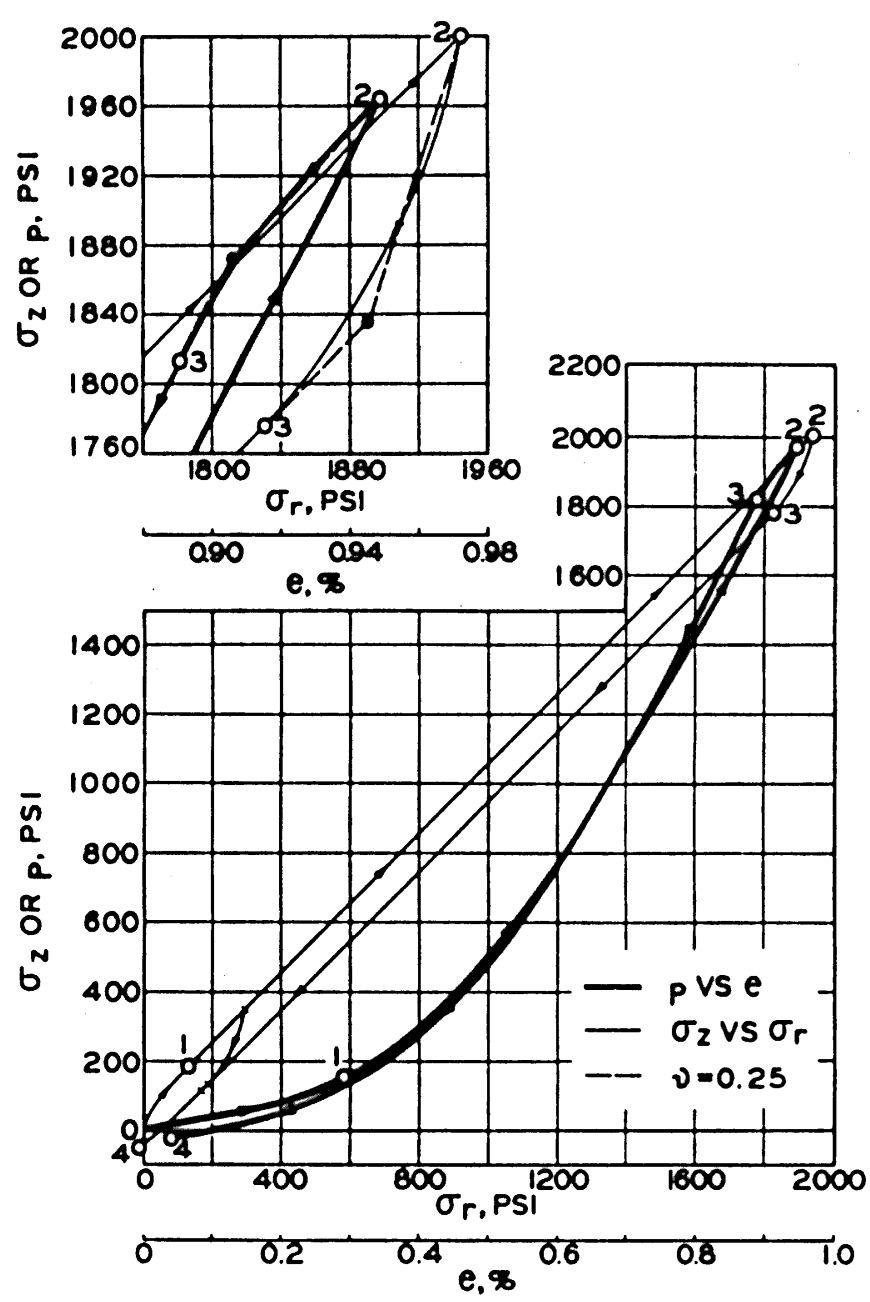

Fig. 12. Extended $\sigma_{z}$ versus $\sigma_{r}$ and $p$ versus $e$ based on trial stress paths for uniaxial strain corner of fig. 12. Again, the light solid line is the $\sigma_{z}$ versus $\sigma_{r}$ relation, and the heavy solid line is the $p$ versus e relation shown looping backwards as it unloads. The dashed lines were plotted from data taken from the trial in which Poisson's ratio was equal to 0.25 and yield essentially the same $p$ versus $e$ curve as the first trial data. 44. Since a model that generates strain energy instead of absorbing it was not considered to be a good solution, it was decided that the extension of the $\sigma_{z}$ versus $\sigma_{r}$ relation to higher pressures might have been done a little hastily. Therefore, determination of the $\sigma_{z}$ versus $\sigma_{r}$ relation that would eliminate this strain reversal in the.

$p$ versus $e$ function at high

pressure by permitting the $p$ versus e curve to at least initially unload along its original loading path was necessary. Such a relation can be calculated from a tabulation of the $\sigma_{z}$ versus $\epsilon_{z}$ values from the representative dynamic uniaxial strain relation given in fig. 4 and the corresponding $p$ values from fig. 12 required to eliminate the reverse hysteresis loop in the $p$ versus e relation. Results given in table 4 and fig. 13 show that when unloading takes place after an extended loading along a yield surface, Poisson's ratio may not drop abruptly to a relatively low value such as 0.25 , but may gradually decrease starting with a much higher 
value such as 0.47 or 0.48 . 45. Naturally, the first step was a review of the pertinent literature to determine if some physical evidence could be found to support the above hypothesis. An excellent example was found in the results of a static uniaxial strain test with radial stress measurements conducted on Suffield silty clay at the University of Illinois; ${ }^{10}$ these test results are plotted in the insert at the upper left-hand corner of fig. 13. The data show loading to a vertical stress of $300 \mathrm{psi}$, followed by an unloading cycle that starts
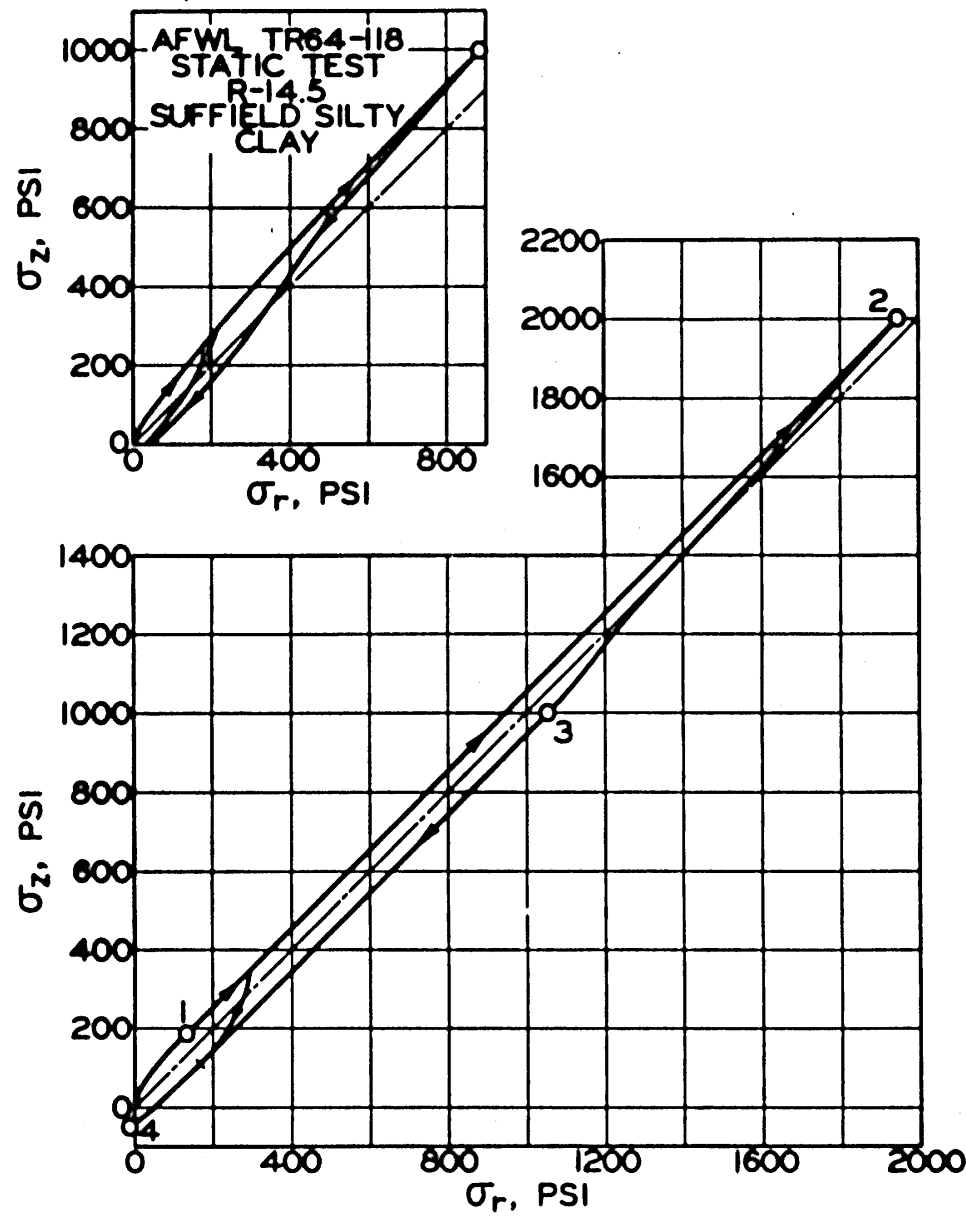

Fig. 13. Adjusted dynamic vertical stress versus radial stress for uniaxial strain with a relatively low Poisson's ratio as did the WES static test data and a subsequent second loading cycle along an apparent yield surface to a much higher vertical stress, from which it unloads with a relatively high Poisson's ratio, i.e., between 0.47 and 0.48 .

46. With this bit of physical evidence as backup, the adjusted dynamic uniaxial strain relation between $\sigma_{z}$ and $\sigma_{r}$ given in fig. 13 was used in the constitutive property calculations. This plot defines Poisson's ratio only for loading from the origin and unloading from $\sigma_{z}$ values of 350 and $2000 \mathrm{psi}$; the next step is to define a general relation for Poisson's ratio that accounts for unloading from any maximum pressure apt to be encountered during the ground shock calculation. To assist in this 

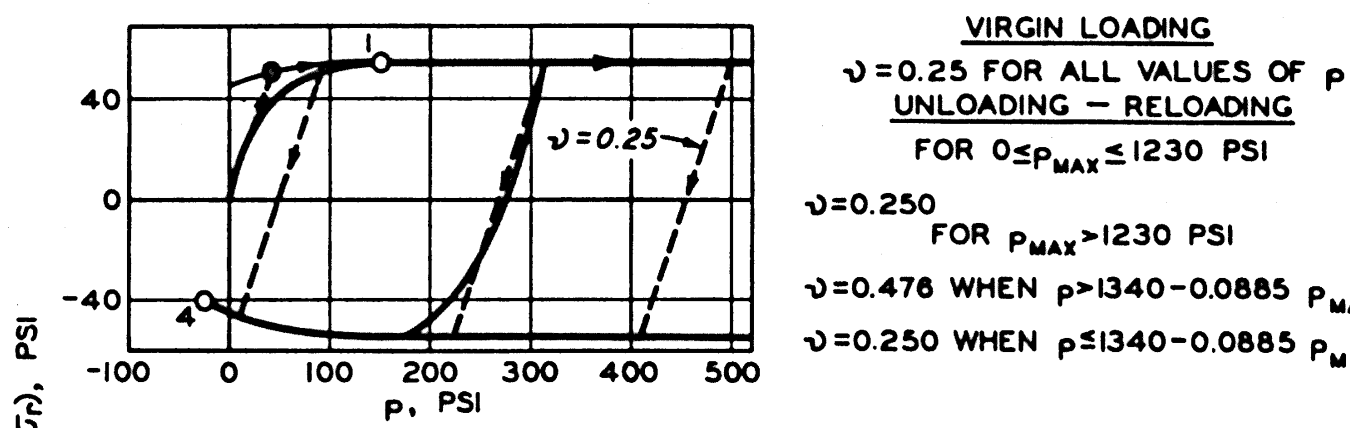

$v=0.250$

FOR $P_{\text {max }}>1230$ PSI

$\nu=0.476$ WHEN $p>1340-0.0885 P_{\text {max }}$

$v=0.250$ WHEN $p \leq 1340-0.0885 P_{\text {max }}$

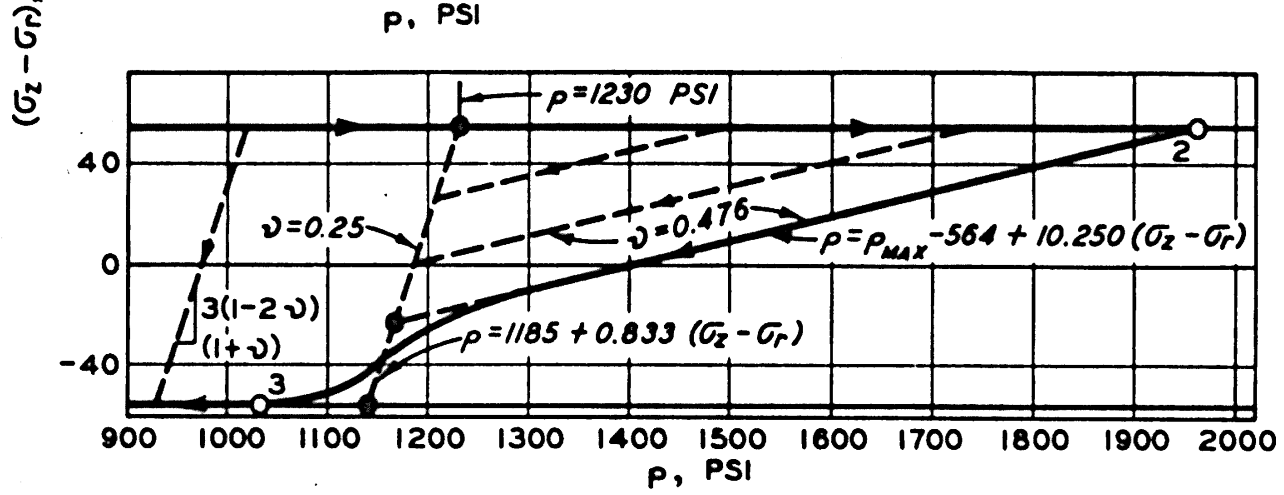

Fig. 14. Adjusted and idealized stress paths for uniaxial strain

step, the $\sigma_{z}$ versus $\sigma_{r}$ relation in fig. 13 was converted to the $\left(\sigma_{z}-\sigma_{r}\right)$ versus $p$ relation shown in fig. 14. The heavy lines in the upper figure show the loading path from the origin and the unloading path for a $p_{\max }$ value corresponding to a $\sigma_{z}$ of 2000 psi followed by unloading along the recently adjusted path.

47. Definition of the actual functional form for these stress paths between yield surfaces and their obvious transitions from one shape to another as pressure increases is an item that requires considerably more testing and study, For the present, Poisson's ratio has simply been defined as having two values, 0.250 and 0.476 , as indicated by the dashed lines in fig. 14. The value of 0.250 is used during any virgin loading and when $p_{\max }$ is less than $1230 \mathrm{psi}$; for $p_{\max }$ values above $1230 \mathrm{psi}$, the Poisson's ratio value of 0.476 is used initially and is changed to the 0.250 value when the unloading path defined by

$$
\mathrm{p}=\mathrm{p}_{\max }-564+10.250\left(\sigma_{z}-\sigma_{r}\right)
$$


intersects the boundary defined by

$$
p=1185+0.833\left(\sigma_{z}-\sigma_{r}\right)
$$

Equations can be written now for dynamic Poisson's ratio as a function of mean pressure, as shown in the upper right-hand corner of fig. 14.

48. Once the dynamic yield envelope and Poisson's ratio functions have been established, they can be combined with the representative dynamic $\sigma_{z}$ versus $\epsilon_{z}$ relation to plot the final dynamic $p$ versus $e$ relation shown by the heavy solid line in fig. 15. However, the unloading slopes for this relation at pressures below about 100 psi are less than those during virgin loading, which violates one of the conditions for the model given in paragraph 6 . To avoid this violation, the unloading "tail" has been stiffened slightly as shown by the dashed line. The final step is to fit both loading and unloading curves with polynomial equations as shown at the top of fig. 15.

Fig. 15. Adjusted dynamic pressure versus volumetric strain relation

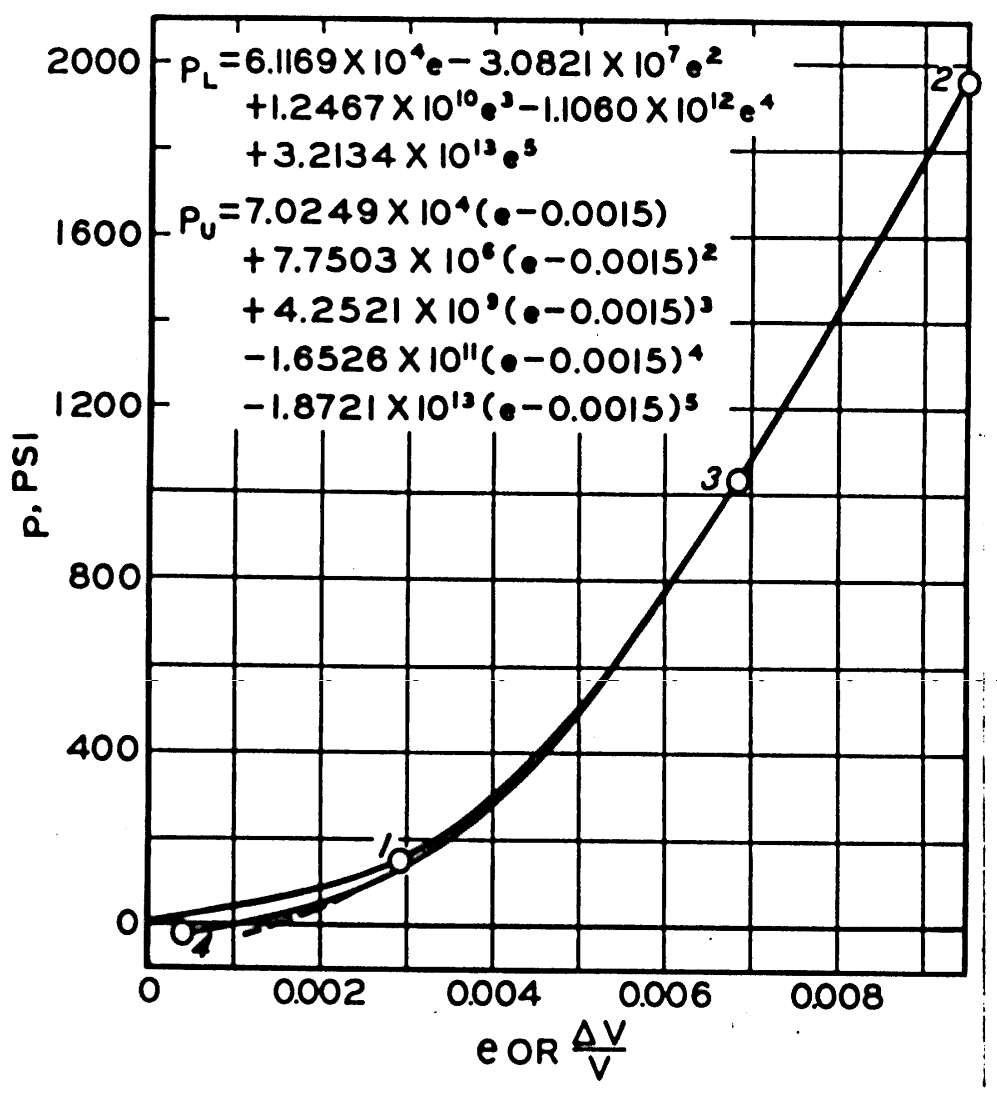


49. Finally, the completed constitutive model is in equation form: for virgin loading

(1)

$$
\begin{aligned}
p_{L}= & 6.1169 \times 10^{4} e-3.0821 \times 10^{7} e^{2}+1.2467 \times 10^{10} e^{3} \\
& -1.1060 \times 10^{12} e^{4}+3.2134 \times 10^{13} e^{5}
\end{aligned}
$$

(2)

$$
\nu_{L}=0.250 \text { for all } p
$$

(3)

$$
\begin{aligned}
\sqrt{J_{2}^{\prime}} & =25.8+95.3 \times 10^{-3} p-37.0 \times 10^{-5} p^{2} \text { for } p<150 \mathrm{psi} \\
& =31.8 \mathrm{psi} \quad \text { for } \mathrm{p} \geq 150 \mathrm{psi}
\end{aligned}
$$

(1)

$$
\begin{aligned}
& \text { for unloading-reloading } \\
& \mathrm{p}_{\mathrm{U}}= 7.0249 \times 10^{4}(\mathrm{e}-0.0015)+7.7503 \times 10^{6}(\mathrm{e}-0.0015)^{2} \\
&+4.2521 \times 10^{9}(\mathrm{e}-0.0015)^{3} \\
&-1.6526 \times 10^{11}(\mathrm{e}-0.0015)^{4} \\
&-1.8721 \times 10^{13}(\mathrm{e}-0.0015)^{5} \\
& \nu_{U}= 0.250 \text { for } 0 \leq \mathrm{p}_{\max } \leq 1230 \\
&= 0.476 \text { for } \mathrm{p}_{\max }>1230 \mathrm{psi} \text { and when } \mathrm{p}>1340-0.0885 \mathrm{p}_{\max } \\
&= 0.250 \text { for } \mathrm{p}_{\max }>1230 \mathrm{psi} \text { and when } \mathrm{p} \leq 1340-0.0885 \mathrm{p}_{\max } \\
& \sqrt{J_{2_{\max }}=}-25.8-95.3 \times 10^{-3} \mathrm{p}+37.0 \times 10^{-5} \mathrm{p}^{2} \text { for } \mathrm{p}<150 \mathrm{psi} \\
&=-31.8 \text { psi for } \mathrm{p} \geq 150 \mathrm{psi}
\end{aligned}
$$

\section{Conclusion}

50. At the beginning, it was stated that a better appreciation for the uncertainties in a constitutive property analysis might be gained from the study reported herein. The many assumptions and adjustments show that the property analysis does not lead to a "closed-form solution." But an attempt was made to keep things logical and orderly and within the realm of 
physical evidence and reasoning, and that in itself is certainly a step in the right direction. It should now be clear that there is considerably more involved in formulating constitutive properties than just conducting a few tests and plotting the results. It should also be obvious that there must be a high degree of cooperation and interchange between the soils engineers and the calculators, and that there are a number of areas of research still open to both.

51. For instance, as far as laboratory tests are concerned, more strain data are needed. Only one strain measurement was used during the entire example analysis: that was the vertical strain from the uniaxial strain tests. Measuring soil strain is very tedious and difficult, but progress is being made in obtaining radial strain measurements during triaxial compression tests which promises to make possible the measurement of several useful modulus properties.

52. More dynamic, high-pressure modulus data are also needed; for while measurement of constrained modulus has been, and most likely will continue to be, of primary importance, other coefficient relations such as shear modulus and Poisson's ratio are equally important for general-purpose two-dimensional models.

53. This leads to a conclusion for the calculators that the constant $\nu$ and constant $G$ type models should be examined carefully in order that behavior under different states and paths of stress can be observed. The unloading-reloading logic used in the code should be inspected to determine specifically what type translations are made to accommodate unloading from any maximum signal and the method used for treating reloading. Another point that needs investigating is whether, in fact, gravity stresses can be accounted for in the calculations by including their effects in the constitutive model rather than by including an added term in the equations of motion.

54. It is hoped that these suggestions for additional tests and for perhaps some improvements in the constitutive models have not left the impression that simply having more test data of more different types and having more generalized constitutive models will simplify the job of defining constitutive properties for code input. Just the opposite will probably be 
the case; i.e., the job will be much more complicated than it is already. This should not deter such efforts, for if the soils engineers and the calculators will continue to work together, it will lead to more realistic models based on more physical facts, and that cannot help but lead to better ground shock calculations. 


\section{Literature Cited}

1. Defense Atomic Support Agency, "Proceedings, Strategic Structures Vulnerability/Hardening Long Range Planning Meeting (U) Held at Air Force Weapons Laboratory 30 January Through 1 February 1968," DASIAC Special Report 72 (DASA-2128), Sept 1968, CONFIDENTIAI.

2. Jackson, J. G. Jr., "Factors That Influence the Development of Soil Constitutive Relations," Miscellaneous Paper No. 4-980, July 1968, U. S. Army Engineer Waterways Experiment Station, CE, Vicksburg, Miss.

3. Kirkpatrick, W. M. and Belshaw, D. J., "On the Interpretation of the Triaxial Test," Geotechnique, Vol 18, No. 3, Sept 1968, pp 336-350.

4. Schindler, L., "Design and Evaluation of a Device for Determining the One-Dimensional Compression Characteristics of Soils Subjected to Impulse-Type Loads," Technical Report S-68-9, Nov 1968, U. S. Army Engineer Waterways Experiment Station, CE, Vicksburg, Miss.

5. Jackson, J. G., Jr., "Uniaxial Strain Testing of Soils for BlastOriented Problems," Miscellaneous Paper S-68-17, Sept 1968, U. S. Army Engineer Waterways Experiment Station, CE, Vicksburg, Miss.

6. Carroll, W. F., "Appendix A: Dynamic Triaxial Testing," Dynamic Bearing Capacity of Soils; Vertical Displacements of Spread Footings on Clay: Static and Impulse Loadings, Technical Report No. 3-599, Report 5, Sept 1963, U. S. Army Engineer Waterways Experiment Station, $\mathrm{CE}$, Vicksburg, Miss.

7. Headquarters, Department of the Army, "Engineering and Design; Laboratory Soil Testing," Engineer Manual No. 1110-2-1906, 10 May 1965, Washington, D. C.

8. Johnson, S. J., "An Alternative Method for Determining the Constrained Modulus and the Coefficient of Elastic Vertical Compression," Aug 1961, Moran̈, Proctor, Mueser \& Rutledge, New York.

9. Hendron, A. J., Jr., Davisson, M. T., and Parola, J. F., "Effect of Degree of Saturation on Compressibility of Soils from the Defense Research Establishment, Suffield," Contract Report (in preparation), U. S. Army Engineer Waterways Experiment Station, CE, Vicksburg, Miss.; prepared by M. T. Davisson, Foundation Engineer, Champaign, Ill.

10. Davisson, M. T. and Maynard, T. R., "Static and Dynamic Compressibility of Suffield Experimental Station Soils," Technical Report No. 64-118, Apr 1965, Air Force Weapons Laboratory, Kirtland Air Force Base, N. Mex. 
Table 1

Most Representative Static Uniaxial Strain Test Results

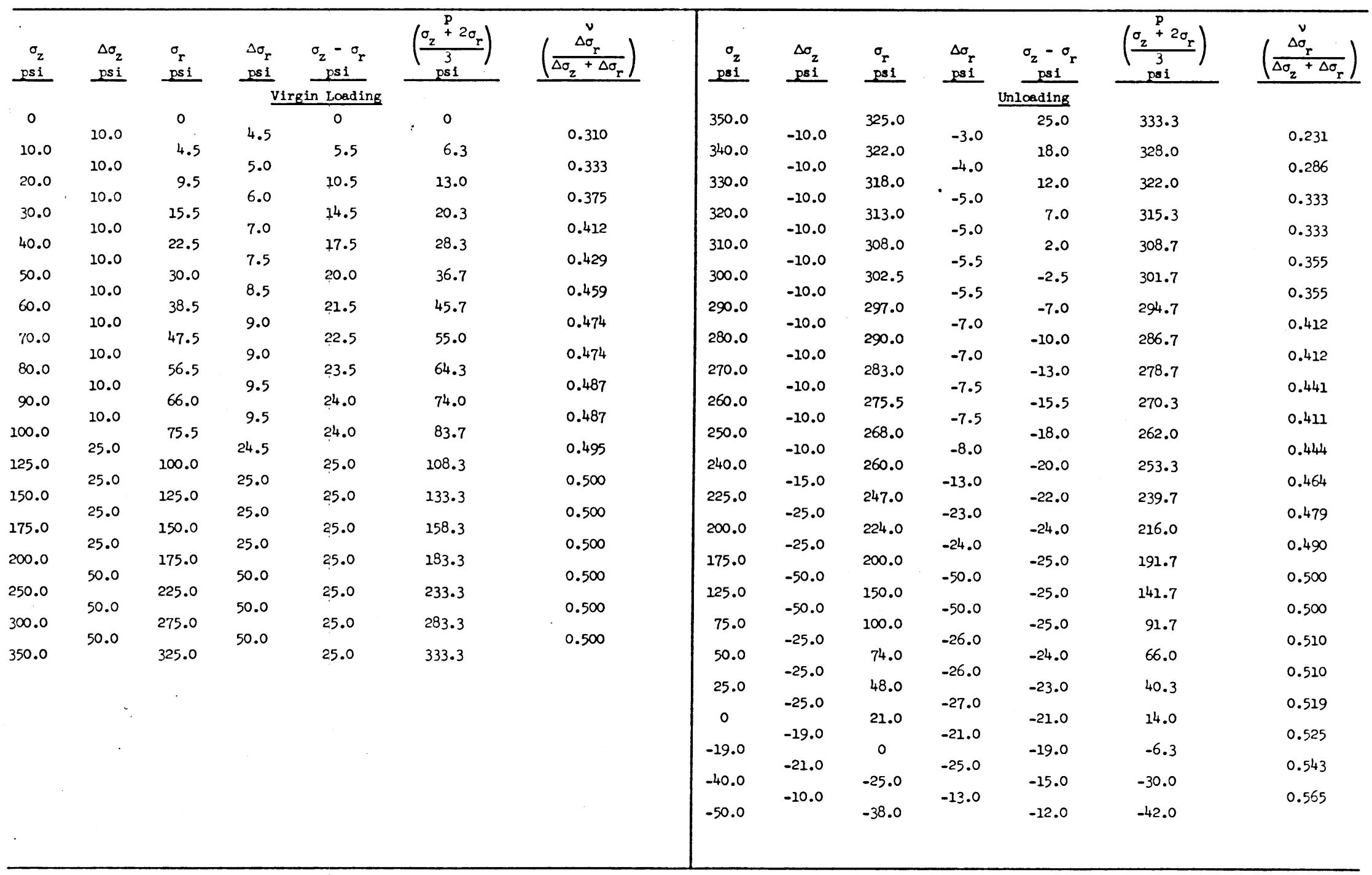


Table 2

Data from First Trial Dymamic Stress Path for Uniexiel Strain

\begin{tabular}{|c|c|c|c|c|c|c|c|c|c|c|c|c|c|c|c|}
\hline Point & $\begin{array}{c}\sigma_{z}-\sigma_{r} \\
\underline{p s i}\end{array}$ & $\left(\frac{\sigma_{z}+2 \sigma_{r}}{3}\right)$ & $\begin{array}{r}\sigma_{r} \\
\text { psi } \\
\end{array}$ & $\begin{array}{l}\Delta_{r} \\
\text { psi } \\
\end{array}$ & $\begin{array}{r}\sigma_{2} \\
\text { psi } 1 \\
\end{array}$ & $\begin{array}{c}\Delta \sigma_{2} \\
p s 1 \\
\end{array}$ & $\left(\frac{\nu_{r}^{\nu}}{\Delta \sigma_{z}+\Delta \sigma_{r}}\right)$ & Point & $\begin{array}{c}\sigma_{2}-\sigma_{Y} \\
\text { psi }\end{array}$ & $\left(\frac{\sigma_{z}+2 \sigma_{x}}{3}\right)$ & $\begin{array}{r}\sigma_{\mathbf{r}} \\
\text { psi } \\
\end{array}$ & $\begin{array}{l}\Delta \sigma_{\mathbf{r}} \\
\text { psi } \\
\end{array}$ & $\begin{array}{r}\sigma_{2} \\
\text { psi }\end{array}$ & $\begin{array}{r}\Delta_{z} \\
\text { psi } \\
\end{array}$ & $\left(\frac{\Delta_{r}^{v}}{\Delta \sigma_{z}+\Delta \sigma_{r}}\right)$ \\
\hline \multirow{3}{*}{ Origin } & \multicolumn{7}{|c|}{ Virgin Loading } & \multicolumn{8}{|c|}{ Unloeding } \\
\hline & 0 & 0 & 0 & \multirow{3}{*}{$\begin{array}{l}2.3 \\
3.0\end{array}$} & \multirow{2}{*}{0} & \multirow{2}{*}{10.3} & \multirow{2}{*}{0.183} & \multirow[t]{2}{*}{ (2) } & \multirow{2}{*}{$\begin{array}{l}55.0 \\
49.0\end{array}$} & \multirow{2}{*}{$\begin{array}{l}313.3 \\
310.0\end{array}$} & 295.0 & \multirow{2}{*}{-1.3} & 350.0 & \multirow{2}{*}{-7.3} & \multirow{2}{*}{0.151} \\
\hline & 8.0 & 5.0 & 2.3 & & & & & & & & 293.7 & & 342.7 & & \\
\hline . & 14.0 & 10.0 & 5.3 & & 19.3 & 9.0 & 0.250 & & 40.0 & 305.0 & 291.7 & -2.0 & 331.7 & -11.0 & 0.154 \\
\hline & 19.6 & 15.0 & 8.5 & J.2 & 28.1 & 0.0 & 0.207 & & 25.0 & 295.0 & 286.7 & -3.0 & 311.7 & -20.0 & 0.200 \\
\hline & 24.5 & 20.0 & u.\& & 3.5 & 36.3 & 0.2 & 0.207 & & 12.0 & 285.0 & 281.0 & -3.7 & 293.0 & -10.7 & 0.234 \\
\hline & 28.5 & 25.0 & 15.5 & 3.7 & 44.0 & 7.7 & 0.325 & & 0 & 274.0 & 274.0 & -7.0 & 274.0 & -19.0 & 0.269 \\
\hline & 32.0 & 30.0 & 19.3 & 3.8 & 51.3 & 7.3 & 0.342 & & -11.0 & 262.5 & 266.2 & -7.8 & 255.2 & -18.8 & 0.293 \\
\hline & 35.0 & 35.0 & 23.3 & 4.0 & 58.3 & 7.0 & 0.364 & & -21.0 & 250.0 & 257.0 & -9.2 & 236.0 & -19.2 & 0.324 \\
\hline & 37.5 & 40.0 & 27.5 & .2 & 65.0 & & 0.385 & & -30.0 & 237.5 & 247.5 & -9.5 & 217.5 & -18.5 & 0.339 \\
\hline & 39.7 & 45.0 & 31.8 & & 71.5 & 6.5 & 0.398 & & -37.0 & 225.0 & 237.3 & -10.2 & $m_{3}$ & -17.2 & 0.372 \\
\hline & 475 & 50.0 & $36=$ & 4.4 & 777 & 6.2 & 0.415 & & oru & & - & -12.6 & 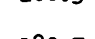 & -19.6 & 0.391 \\
\hline & & & & 8.8 & & 12.3 & 0.417 & & & & $<<4.1$ & -13.0 & 100.1 & -19.0 & 0.406 \\
\hline & 45.0 & 60.0 & 45.0 & 9.2 & 90.0 & 11.7 & 0.440 & & -50.0 & 195.0 & 211.7 & -7.4 & 161.7 & -9.4 & 0.440 \\
\hline & 47.5 & 70.0 & 54.2 & 04 & 101.7 & ? & 0.456 & & -52.0 & 187.0 & 204.3 & 3 & 152.3 & -132 & 0150 \\
\hline & 49.3 & 80.0 & 63.6 & & 122.9 & 2. & (1) & & -54.0 & 175.0 & 193.0 & 7 & 139.0 & 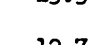 & (2) \\
\hline & 51.0 & 90.0 & 73.0 & & 124.0 & 1.1 & 0.439 & (3) & -55.0 & 163.0 & 181.3 & II. & 126.3 & -12.7 & 0.480 \\
\hline & 52.5 & 100.0 & 82.5 & प.) & 135.0 & 11.0 & 0.463 & & -55.0 & 150.0 & 168.3 & -13.0 & 113.3 & -13.0 & 0.500 \\
\hline & 54.3 & 125.0 & 106.9 & & 161.2 & 20.2 & 0.402 & & -54.0 & 100.0 & 118.0 & 50.3 & 64.0 & 49.3 & 0.505 \\
\hline (1) & 55.0 & 150.0 & 131.7 & & 186.7 & 25.5 & 0.493 & & -53.0 & 75.0 & 92.7 & -25.3 & 39.7 & -24.3 & 0.510 \\
\hline & 55.0 & 2000 & 187 & 50.0 & 2367 & 50.0 & 0.500 & & -510 & $\ln 0$ & O4.0 & -28.7 & & -26.7 & 0.518 \\
\hline & 32.0 & 200.0 & 101.8 & 113.3 & 230.7 & 113.3 & 0.500 & & -31.0 & 47.0 & 64.0 & -28.0 & 13.0 & -25.0 & 0.528 \\
\hline (2) & 55.0 & 313.3 & 295.0 & & 350.0 & & & & -48.0 & 20.0 & 36.0 & -21.0 & -12.0 & -18.0 & 0.538 \\
\hline & & & & & & & & & -45.0 & 0 & 15.0 & & -30.0 & & \\
\hline & & & & & & & & (4) & -40.0 & -23.3 & -10.0 & -23.0 & -50.0 & -20.0 & 0.335 \\
\hline
\end{tabular}


Table 3

Extended First Trial $\sigma_{z}$ versus $\sigma_{r}$ and $p$ versus e

\section{for Dymamic Uniaxial Strain}

\begin{tabular}{|c|c|c|c|c|c|c|}
\hline Point & $\begin{array}{r}\sigma_{z} \\
p s i \\
\end{array}$ & $\left(\begin{array}{c}\varepsilon_{z} \\
\frac{\Delta V}{V_{o}} \\
\%\end{array}\right)$ & $\begin{array}{c}\mathrm{e} \\
\left(\frac{\Delta \mathrm{V}}{\mathrm{V}}\right) \\
\%\end{array}$ & $\begin{array}{l}\sigma_{r} \\
\text { psi }\end{array}$ & $\left(\frac{\sigma_{z}+2 \sigma_{r}}{3}\right)$ & $\begin{array}{c}\sigma_{z}-\sigma_{r} \\
p_{p s i}\end{array}$ \\
\hline Origin & $\begin{array}{l}0 \\
20 \\
40 \\
60 \\
80\end{array}$ & $\begin{array}{l}0 \\
0.020 \\
0.050 \\
0.085 \\
0.140\end{array}$ & $\begin{array}{l}0 \\
0.020 \\
0.050 \\
0.085 \\
0.140\end{array}$ & $\begin{array}{r}0 \\
5 \\
13 \\
24 \\
38\end{array}$ & $\begin{array}{r}0 \\
10 \\
22 \\
36 \\
52\end{array}$ & $\begin{array}{r}0 \\
15 \\
27 \\
36 \\
42\end{array}$ \\
\hline \multirow[t]{3}{*}{ (1) } & $\begin{array}{l}100 \\
120 \\
140 \\
160 \\
186.7\end{array}$ & $\begin{array}{l}0.175 \\
0.205 \\
0.235 \\
0.260 \\
0.290\end{array}$ & $\begin{array}{l}0.175 \\
0.205 \\
0.236 \\
0.261 \\
0.291\end{array}$ & $\begin{array}{c}53 \\
70 \\
88 \\
107 \\
131.7\end{array}$ & $\begin{array}{r}69 \\
87 \\
105 \\
125 \\
150\end{array}$ & $\begin{array}{l}47 \\
50 \\
52 \\
53 \\
55\end{array}$ \\
\hline & $\begin{array}{l}200 \\
240 \\
280 \\
320 \\
350\end{array}$ & $\begin{array}{l}0.300 \\
0.335 \\
0.365 \\
0.390 \\
0.410\end{array}$ & $\begin{array}{l}0.301 \\
0.336 \\
0.366 \\
0.392 \\
0.412\end{array}$ & $\begin{array}{l}145 \\
185 \\
225 \\
265 \\
295\end{array}$ & $\begin{array}{l}163 \\
203 \\
243 \\
283 \\
313\end{array}$ & $\begin{array}{l}55 \\
55 \\
55 \\
55 \\
55\end{array}$ \\
\hline & $\begin{array}{r}400 \\
500 \\
600 \\
700 \\
1000\end{array}$ & $\begin{array}{l}0.435 \\
0.480 \\
0.520 \\
0.560 \\
0.660\end{array}$ & $\begin{array}{l}0.437 \\
0.482 \\
0.522 \\
0.563 \\
0.664\end{array}$ & $\begin{array}{l}345 \\
445 \\
545 \\
645 \\
945\end{array}$ & $\begin{array}{l}363 \\
463 \\
563 \\
663 \\
963\end{array}$ & $\begin{array}{l}55 \\
55 \\
55 \\
55 \\
55\end{array}$ \\
\hline (2) & $\begin{array}{l}1500 \\
2000 \\
1950 \\
1900 \\
1850\end{array}$ & $\begin{array}{l}0.805 \\
0.940 \\
0.930 \\
0.915 \\
0.900\end{array}$ & $\begin{array}{l}0.812 \\
0.949 \\
0.938 \\
0.923 \\
0.908\end{array}$ & $\begin{array}{l}1445 \\
1945 \\
1933 \\
1913 \\
1886\end{array}$ & $\begin{array}{l}1453 \\
1963 \\
1939 \\
1909 \\
1874\end{array}$ & $\begin{array}{r}55 \\
55 \\
17 \\
-13 \\
-36\end{array}$ \\
\hline \multirow[t]{3}{*}{ (3) } & $\begin{array}{l}1800 \\
1776 \\
1700 \\
1500 \\
1300\end{array}$ & $\begin{array}{l}0.890 \\
0.883 \\
0.865 \\
0.815 \\
0.760\end{array}$ & $\begin{array}{l}0.898 \\
0.891 \\
0.873 \\
0.817 \\
0.766\end{array}$ & $\begin{array}{l}1852 \\
1831 \\
1755 \\
1555 \\
1355\end{array}$ & $\begin{array}{l}1835 \\
1813 \\
1737 \\
1537 \\
1337\end{array}$ & $\begin{array}{l}-52 \\
-55 \\
-55 \\
-55 \\
-55\end{array}$ \\
\hline & $\begin{array}{r}1000 \\
700 \\
500 \\
400 \\
300\end{array}$ & $\begin{array}{l}0.680 \\
0.585 \\
0.520 \\
0.475 \\
0.430\end{array}$ & $\begin{array}{l}0.685 \\
0.588 \\
0.523 \\
0.477 \\
0.432\end{array}$ & $\begin{array}{r}1055 \\
755 \\
555 \\
455 \\
355\end{array}$ & $\begin{array}{r}1037 \\
737 \\
537 \\
437 \\
337\end{array}$ & $\begin{array}{l}-55 \\
-55 \\
-55 \\
-55 \\
-55\end{array}$ \\
\hline & $\begin{array}{l}200 \\
126.3 \\
113.3 \\
60 \\
20\end{array}$ & $\begin{array}{l}0.370 \\
0.315 \\
0.305 \\
0.255 \\
0.205\end{array}$ & $\begin{array}{l}0.371 \\
0.316 \\
0.306 \\
0.256 \\
0.205\end{array}$ & $\begin{array}{l}255 \\
181.3 \\
168.3 \\
114 \\
71\end{array}$ & $\begin{array}{r}237 \\
163 \\
150 \\
96 \\
54\end{array}$ & $\begin{array}{l}-55 \\
-55 \\
-55 \\
-54 \\
-51\end{array}$ \\
\hline (4) & $\begin{array}{r}0 \\
-20 \\
-50\end{array}$ & $\begin{array}{l}0.170 \\
0.130 \\
0.040\end{array}$ & $\begin{array}{l}0.170 \\
0.130 \\
0.040\end{array}$ & $\begin{array}{r}49 \\
26 \\
-11\end{array}$ & $\begin{array}{r}33 \\
11 \\
-24\end{array}$ & $\begin{array}{l}-49 \\
-46 \\
-39\end{array}$ \\
\hline
\end{tabular}


Table 4

Adjustment of Dynamic $\sigma_{z}$ versus $\sigma_{r}$ to Eliminate

Reverse Hysteresis in $p$ versus $e$

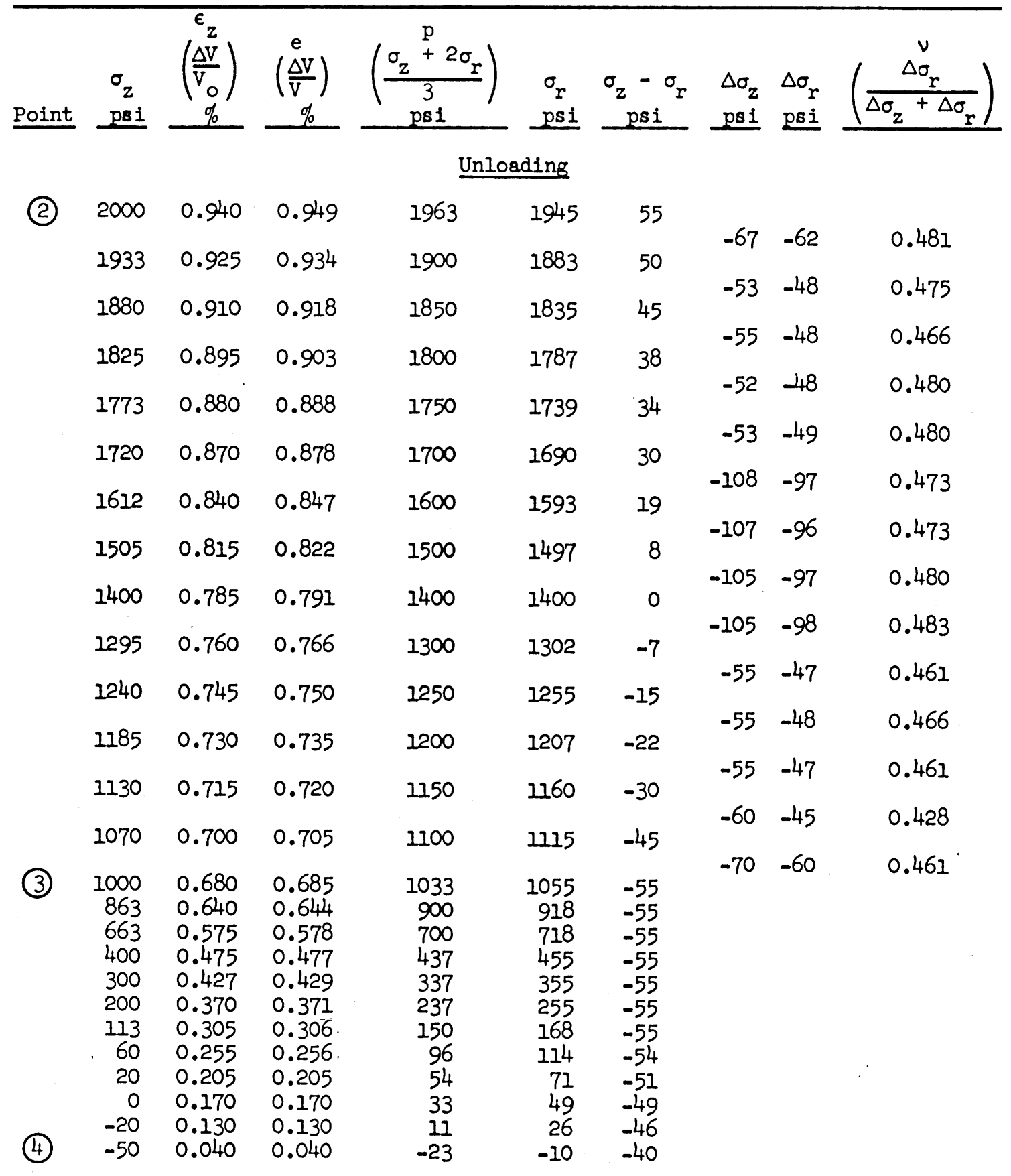




\begin{tabular}{|c|c|c|}
\hline \multicolumn{3}{|c|}{$\begin{array}{l}\text { DOCUMENT CONTROL DATA } \\
\text { isecurlty eleaslification of iltle, body of abstract and indexine annolation mus }\end{array}$} \\
\hline \multirow{2}{*}{\multicolumn{2}{|c|}{$\begin{array}{l}\text { U. S. Army Engineer Waterways Experiment Station } \\
\text { Vicksburg, Miss. }\end{array}$}} & $\begin{array}{l}\text { 20. REPOAT SECURITY CLASBIFICATION } \\
\text { UnClassified }\end{array}$ \\
\hline & & 2b. Gnoup \\
\hline \multicolumn{3}{|l|}{ 3. REPOAT TITLE } \\
\hline \multicolumn{3}{|c|}{ ANALYSIS OF IABORATORY TEST DATA TO DERIVE SOII CONSTITUTIVE PROPERTIES } \\
\hline \multicolumn{3}{|l|}{$\begin{array}{l}\text { 4. OEschiptive Notes (Typo of roparl and Incluelve datee) } \\
\text { Final report }\end{array}$} \\
\hline \multicolumn{3}{|l|}{ D. AU THOAISI (Prot name, anlddio InIllal, laet name) } \\
\hline $\begin{array}{l}\text { A. RTPOAT DATE } \\
\text { April } 1969\end{array}$ & \multicolumn{2}{|c|}{\begin{tabular}{|c|c|} 
79. TOTAL NO. OF PAGES & $\begin{array}{c}\text { 7b. NO. OF REFS } \\
36\end{array}$ \\
\end{tabular}} \\
\hline b. PnOsect no. & 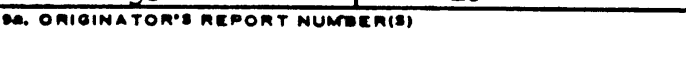 & Miscellaneous Paper S-69-16 \\
\hline c. & \multicolumn{2}{|c|}{$\begin{array}{l}\text { 6b. OTHER REPOAT NO(S) (Any other nuenbere thet way be aeelened } \\
\text { enie roport) }\end{array}$} \\
\hline
\end{tabular}

This document has been approved for public release and sale; its distribution is unlimited.

\begin{tabular}{|c|}
\hline $\begin{array}{l}\text { 12. SPOnsoning miLITARY ACTIVITY } \\
\text { Defense Atomic Support Agency } \\
\text { Washington, D. C. }\end{array}$ \\
\hline $\begin{array}{l}\text { Acsmact Computer codes used in the solution of free-field ground shock problems are } \\
\text { based on mathematically defined constitutive models. Quantitative input for these } \\
\text { constitutive models is primarily based on laboratory test data, but extensive analy- } \\
\text { sis and numerous assumptions are required to convert these data to a form suitable for } \\
\text { actual code input. This report presents a detailed illustration of the analyses in- } \\
\text { volved in deriving the soil constitutive properties required for a specific code for- } \\
\text { mulation using laboratory test data from just one stratum of a single site. Data are } \\
\text { available from static and dynamic uniaxial strain and triaxial shear tests; code prop- } \\
\text { erty requirements are for mathematical expressions relating mean pressure to volu- } \\
\text { metric strain, Poisson's ratio to mean pressure, and a plastic yield criterion to mean } \\
\text { pressure. The illustration indicates that progress is being made in developing mathe- } \\
\text { matical constitutive models that are realistic in terms of actual physical behavior, } \\
\text { but that if many of the assumptions presentiy being made in soil property analyses } \\
\text { are to be eliminated, additional soil tests and measurements must be developed. The } \\
\text { illustration also raises questions as to the validity of models based on a constant } \\
\text { Poisson's ratio or a constant shear modulus and suggests that the behavior of the var- } \\
\text { ios modelsor }\end{array}$ \\
\hline
\end{tabular}


Unclassified

Security Cleseification

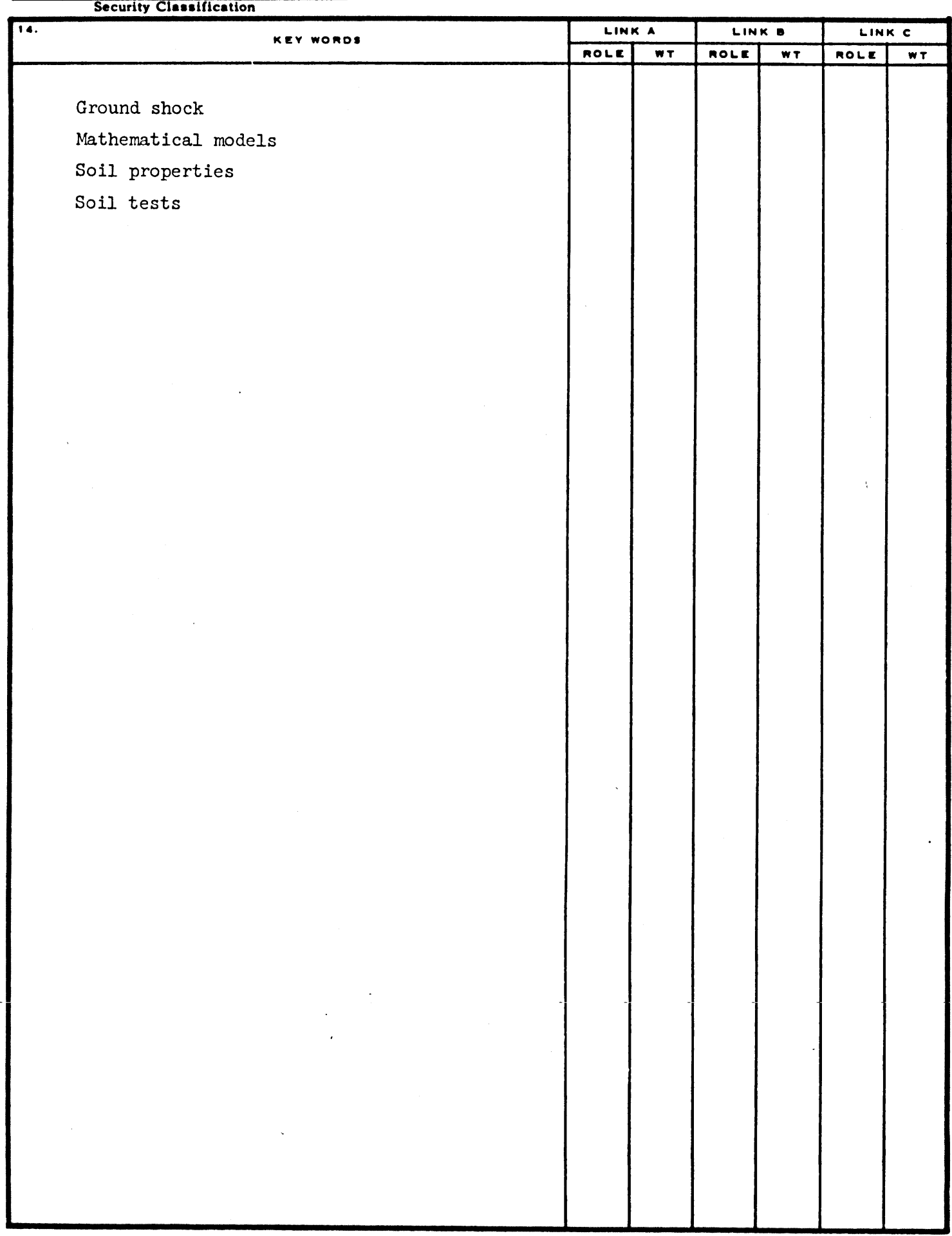

Unclassified

Security Claselfication 